\title{
La comercialización de los juegos de la ONCE y su incidencia en el ámbito autonómico y local
}

\author{
Juan Francisco Pérez Gálvez \\ Profesor Titular de Derecho Administrativo \\ Universidad de Almería
}

Sumario: I. JUSTIFICACIÓN DE ESTE TRABAJO: HOMENAJE A UNA PUBLICACIÓN QUE SE HA CONVERTIDO EN SEÑA DE IDENTIDAD DEL DERECHO AUTONÓMICO Y LOCAL. II. EL JUEGO: EVOLUCIÓN HISTÓRICA Y COMPETENCIAL. 1. Evolución social y legislativa. 2. La disyuntiva competencial: Estado versus Comunidades Autónomas. III. EL CUPÓN DE LA ORGANIZACIÓN NACIONAL DE CIEGOS ESPAÑOLES. 1. Aproximación conceptual. 2. Naturaleza jurídica. 3. Clasificación. 3.1. Lotería instantánea o presorteada y lotería condicionada a la realización del sorteo. 3.2. Tipos de soporte para el cupón: el cupón preimpreso y el cupón emitido por Terminal de punto de venta. 3.3. Formas de comercialización del cupón preimpreso: cupones de un único sorteo y cupones de varios sorteos, también denominados abono semanal. 3.4. Formas de comercialización del cupón emitido por Terminal de punto de venta. 3.5. Modalidades de comercialización: tipología de juegos. 3.5.1. Sorteo del cupón de lunes a jueves. 3.5.2. Sorteo del cupón de los viernes, con un premio especial a un solo cupón de 6 millones de euros. 3.5.3. Sorteo del cupón de «Fin de Semana». 3.5.4. Abono semanal: bono-cupón. 3.5.5. Sorteo de «El Combo». 3.5.6. Sorteo extraordinario. 3.5.7. Lotería instantánea o presorteada. 3.5.8. Los que puedan autorizarse en el futuro. IV. LA COMERCIALIZACIÓN DE LOS JUEGOS DE LA ONCE EN EL DOMINIO PÚBLICO LOCAL. 1. El quiosco de la ONCE: hito y rito asentado en el dominio público. 2. Régimen jurídico de la determinación del precio público por la ocupación de espacio en la vía pública. 2.1. Consideraciones preliminares. 2.2. La jurisprudencia del Tribunal Constitucional. 2.3. La jurisprudencia del Tribunal Supremo. 3. Responsabilidad patrimonial: la competencia sobre la conservación y policía del dominio público municipal.

\section{JUSTIFICACIÓN DE ESTE TRABAJO: HOMENAJE A UNA PUBLICACIÓN QUE SE HA CONVERTIDO EN SEÑA DE IDENTIDAD DEL DERECHO AUTONÓMICO Y LOCAL}

La justificación de este trabajo se encuentra en la amable invitación para participar mediante la redacción de una colaboración para el número 300 de la Revista de Estudios de la Administración Local y Autonómica, como justo homenaje a una publicación que se ha convertido en seña de identidad del derecho autonómico y local.

La conmemoración de este aniversario - logro digno de mención - con un número especial, ha sido el pretexto utilizado para abordar una materia escasamente tratada por los administrativistas. 
Con la esperanza de contribuir a tan merecido tributo, entrego estas páginas como reconocimiento público a cuantos a través de los años han hecho posible tan destacado logro.

\section{EL JUEGO: EVOLUCIÓN HISTÓRICA Y COMPETENCIAL ${ }^{1}$}

\section{Evolución social y legislativa}

La evolución histórica sobre el juego ${ }^{2}$ ha sido estudiada por la doctrina ${ }^{3}$ haciendo referencia a Las Partidas donde se recogen los principios expuestos en el Derecho romano sobre la materia del juego, el ordenamiento de las tafurerías, obra atribuida al Maestre Roldán, que fue promulgada en el año 1314 por el Rey Alfonso X, la Nueva y Novísima Recopilación, la Prágmática de 6 de octubre de 1771, dada por Carlos III en San Lorenzo, y otras disposiciones que en general prohíben el juego y las rifas, pero con la posibilidad de realizarlas si se obtiene una licencia real para ello. Sobre todo en las últimas disposiciones se hace patente el hecho de que el juego representa una ganancia para el Estado y en el caso de las rifas la posibilidad de excepcionar la prohibición si se obtiene el permiso real ${ }^{4}$.

\footnotetext{
${ }^{1}$ Vide Johan Huizinga, Homo ludens, sexta reimpresión, Alianza Editorial, Madrid, 1996, p. 11: «El juego es más viejo que la cultura; pues, por mucho que estrechemos el concepto de ésta presupone siempre una sociedad humana, y los animales no han esperado a que el hombre les enseñara a jugar. Con toda seguridad podemos decir que la civilización humana no ha añadido ninguna característica esencial al concepto del juego».

2 Vide Luís DíEz PICAZo, «El juego y la apuesta en el Derecho Civil», Revista Crítica de Derecho Inmobiliario, 460, (1967), pp. 723-727, donde realiza un análisis doctrinal sobre los conceptos de «juego» y «apuesta». En la p. 727 afirma: «En un sentido muy amplio, la apuesta es una situación jurídica en la cual una o varias personas quedan obligadas a realizar en favor de otra u otras una prestación que se hace depender de la exactitud o acierto sobre un acontecimiento pretérito o futuro, que en ocasiones es el resultado de un juego».

${ }^{3}$ Vide: Felipe CRESPO DE LARA, Los juegos ilícitos ante las leyes vigentes: la crítica y la democracia (Los tahures y sus trampas), Imprenta de los hijos de Gómez Fuentenebro, calle Bordadores, 10, Madrid, 1912, pp. 74-80: «Legislación española antigua y moderna sobre el juego»; María Lourdes RAMIS Rebassa, Régimen jurídico del juego, Marcial Pons, Madrid, 1992, pp. 23-34; Comisión NACIONAL DeL Juego (Ministerio Del InTERIOR), Libro blanco del juego, Madrid, 1986, pp. 25-31; DirecCión GeneRal de Tributos (Ministerio De Hacienda), «La fiscalidad del juego», Boletín de Información de la Dirección General de Tributos, 2, (1980), p. 6; Luis LóPEZ TORRUBIA, «Economía del juego», Boletín de Información Comercial Española, 597, (1983), pp. 37-38.

${ }^{4}$ Vide Juan García Pesarrodona, Régimen jurídico-administrativo de las asociaciones, Barcelona, 1950, pp. 158-159: «Son lícitos o permitidos, cualquiera que sea su naturaleza o su denominación, cuando su móvil no es la codicia, cuando se utilizan para dar descanso o distraer la imaginación, o para el ejercicio del cuerpo.

Son lícitos, concretamente, según el artículo 1800 del Código civil, «los que tienen por objeto adiestrarse en el manejo de las armas (tiro, esgrima, etc), las carreras a pie o a caballo (pedestrismo, hipismo), las de carros, el juego de pelota y otros de análoga naturaleza, es decir, todas aquellas actividades que constituyen actualmente la finalidad esencial de las asociaciones deportivas, de cuyo régimen especial nos ocupamos más adelante.
} 


\author{
Resulta significativo el contenido de la Real Orden Circular de 14 de sep- \\ tiembre de 1888 , regla $4^{\text {a }}$ :
}

«Cuando el delito se cometa en el local perteneciente a las asociaciones de cualquier clase o en círculos de recreo o casinos en los cuales se juegue habitualmente a juegos ilícitos o prohibidos, aunque sea otro el objeto ostensible de la asociación, V.S. (se alude a los Gobernadores Civiles), deberá perseguirlo teniendo en cuenta que en estos casos procede la pena de suspensión y en su caso la de disolución, a que se refieren el párrafo $2^{\circ}$ del art. 12, y el art. 15 de la Ley de Asociaciones y el correspondiente del Código Penal, por considerarlas casas de juego a los efectos del art. 358, con arreglo a la Sentencia del Tribunal Supremo de 15 de octubre de $1880 \gg^{5}$.

Resulta ilustrativo el discurso de ingreso, leído en el acto de su recepción en la Real Academia de Ciencias Morales y Políticas, por el Excmo. Señor D. Alfredo de Zavala titulado: «Algunas reflexiones sobre los juegos prohibidos» ${ }^{6}$, donde señala:

«El Estado, como representante incoercible de la colectividad social, cumple su misión histórica realizando el Derecho, como se decía en mi tiempo, y adoptando medidas tutelares encaminadas a impedir a los súbditos la ejecución de actos ruino-

\begin{abstract}
Se consideran también lícitos, aun cuando no figuren en la enumeración del Código, los juegos siguientes: billar, frontón, bolos, ajedrez y en general todos aquellos en que entre el cálculo, la destreza y la habilidad del jugador, como se dice en la Circular del Ministerio de la Gobernación de 14 de septiembre de 1888, y por consiguiente, todos aquellos en que no intervenga exclusivamente la suerte, el envite o el azar.
\end{abstract}

A mayor abundamiento, la Circular de fecha 14 de octubre de 1889 de la Fiscalía del Tribunal Supremo, dirigida a los Gobernadores Civiles de provincia, establece que «aquellos juegos en que el ganar o perder dependa de la destreza, inteligencia o práctica de los jugadores, interviniendo secundariamente la suerte, son lícitos y que los demás son ilícitos»».

5 Vide: Sentencia del Tribunal Supremo de 7 de diciembre de 1899: «Toda persona individual o colectiva que establezca o consienta el juego prohibido en un local sometido a su disposición, dirección o gerencia, debe ser reputada como dueño de casa de juego y, por consiguiente, las Juntas directivas de las asociaciones de recreo o de cualquiera otra clase, que autoricen o toleren los juegos prohibidos en el domicilio social, con las circunstancias expresadas, incurren en la responsabilidad que define el art. 358 del Código Penal y, por lo tanto, deben ser castigados con arreglo al mismo artículo los individuos que constituyan aquella Junta o Gerencia, porque son responsables de todo lo que en este punto se establezca o consienta durante el ejercicio de su dirección, ya medie malicia, ya resulte falta de vigilancia en el cumplimiento de los deberes de su cargo»; Sentencia del Tribunal Supremo de 14 de marzo de 1891: «El hecho material de encontrarse una persona en el local donde se juegue, no implica natural y forzosamente el concepto de jugador, porque sólo merece este dictado el que realmente toma parte de alguna manera en el juego».

${ }^{6}$ El ejemplar que llega a mis manos, y cuya contestación fue formulada por Don Niceto Alcalá-Zamora, el día 17 de junio de 1923, corresponde a una impresión realizada por el establecimiento tipográfico de R. Caro Reaggio, Calle de Mendizábal, 34, Madrid. El fragmento reproducido se encuentra en las pp. 13-15. En las pp. 18-19 afirma: «[...]. A esta variedad de conceptos penales se contraponen afirmaciones de licitud, contenidas expresa o tácitamente en otras disposiciones de orden administrativo o de naturaleza civil o procesal. Figuran al frente de ellas los que han erigido la lotería en institución nacional, fuente de importantes ingresos para el Tesoro público; [...]. En la lotería, es el Estado el empresario de la combinación más aleatoria que cabe imaginar. [...]. Perseguir, después de esto, a los que se reúnen para jugar, es una injusticia y un contrasentido. [...]». 
sos, o a neutralizar, contener o atenuar sus consecuencias. Parece, a primera vista, que la mayoría de edad debería revestir al feliz poseedor de los veintitrés años de la prudencia, la sagacidad y la serenidad necesarias para regirse por sí mismo; y en verdad que no hay dique legal contra el que choque la regia voluntad del emancipado en todo lo que se refiere al cuidado, conservación, desprecio o destrucción de su persona. [...].

Y como el juego de azar, suerte o envite, es causa inevitable de ruina, la ley ha extremado sus medidas de rigor, y en vez de limitarse a autorizar el ejercicio de acciones revocatorias y la alegación de excepciones enervadoras, respectivamente dirigidas a recuperar lo perdido y entregado o a resistir su pago, conmina al jugador con responsabilidades de orden penal, de todo punto extrañas a su buena o mala fortuna. $\mathrm{Y}$ en verdad que si pudiera apoyarse tan severa actitud en consideraciones exclusivamente morales, se hallaría plenamente justificada.

El jugador desvía su actividad de toda aplicación útil y pugna por adquirir o aumentar la riqueza propia a costa de la ruina de sus competidores. Empieza aventurando los recursos que legítimamente le pertenecen y acaba por consumir el patrimonio ajeno en la llama de su pasión devoradora. [...]. Para redimirle de la esclavitud a que su vicio le somete, sería necesario que le fundieran de nuevo «como funden las campanas»; y el legislador, ante la imposibilidad de realizar tal obra de transformación fabril, ha recurrido al arbitrio de castigar como delincuentes a los que se reúnen para jugar y a los dueños de las casas donde son recibidos. [...]» ${ }^{7,8}$.

\footnotetext{
${ }^{7}$ Vide José $\mathrm{M}^{\mathrm{a}}$ VALDÉs y Rubio, «Informe presentado al Congreso con motivo del Proyecto de Ley para reglamentar los juegos de suerte, envite o azar», Revista General de Legislación y Jurisprudencia, T. CXXI, (1912), pp. 5-40. Tienen especial interés las conclusiones expuestas en la p. 40:

$\ll 1^{\text {a }}$. Por las fundadas razones de moralidad, justicia y patriotismo expuestas en este informe, debe ser retirado inmediatamente el proyecto de ley que en la apariencia de regularización de los juegos de suerte, envite o azar, osea de los verificados con ánimo de lucro, y que, en realidad, si fuese aprobado sería causa del aumento de otros muchos delitos y de gravísimos males sociales, y aun autorización de los mismos.
}

$2^{\mathrm{a}}$. En sustitución de dicho proyecto de ley debe ser presentado otro por el Excmo. Sr. Ministro de Hacienda, suprimiendo por los mismos motivos expuestos en este informe, la Lotería llamada Nacional, y prohibiendo y penando la celebración de cualquiera otra Lotería o rifa.

$3^{\text {a }}$. El Estado fomentará el trabajo y el ahorro nacionales, inspirando por medio de la educación, la vocación y la práctica de las virtudes individuales y cívicas, contribuyendo al mejoramiento moral y corporal de la raza española a la vez que procura desarrollar el Instituto Nacional de Previsión, las Cajas de Ahorro escolar y postal y todas cuantas fundaciones coadyuven a realizar el progreso patrio.

Y $4^{\text {a }}$. Estando comprobado que disminuyen los juegos de suerte, envite o azar en las naciones en que aumenta la importancia de los ejercicios corporales colectivos, el Estado español estimulará, fomentará y premiará éstos, por ser convenientes en sumo grado para la moralidad de las costumbres y para la Higiene».

${ }^{8}$ Vide José M ${ }^{a}$ CORdoncillo SAmada, Historia de la Real Lotería en Nueva España (1770-1821), Dirección General de Tributos Especiales del Ministerio de Hacienda, Escuela de Estudios Hispano-Americanos, Sevilla, 1962, pp. 13-14. El camino recorrido en el seno del continente americano, presentaba caracteres similares a los que se esgrimían en nuestro país. La situación se justificaba de la siguiente manera:

«Así pues, la natural propensión por los juegos, de criollos, indios y mestizos, extendió su interés a todos. Todas las clases sociales llegaron a practicar el juego; la desenfrenada pasión por éstos, sobre todo, los juegos privados y los de suerte, ocasionó, en efecto, la desunión y las rutinas de muchas familias 
LA COMERCIALIZACIÓN DE LOS JUEGOS DE LA ONCE Y SU INCIDENCIA...

\section{En ocasiones, el juego y la política se entrecruzaron con resultados escan- dalosos:}

«En la legislatura de 1911-1912 toma la palabra en el congreso el diputado Pablo Iglesias y, entre otros asuntos, planteaba el problema del juego en Barcelona, «porque en aquella ciudad ha alcanzado proporciones verdaderamente espantosas; ha habido suicidios, quiebras, ruina de familias, todo ocasionado por la licencia que en el juego reina. Allí ya no es un solo establecimiento el autorizado, sino que son muchos, y sobre esto, como quiera que si bien se intentó a última hora poner remedio, el remedio ha durado sólo unos cuantos días y ahora vuelven a funcionar todas las timbas y garitos con perfectísima libertad» (Diario, 5 de marzo de 1912, VIII, p. 2735).

Aquella interpelación al ministro de gobernación iba a desatar una larga discusión, en donde se muestra la exacta realidad de los juegos tolerados, en torno a los cuales se entreve connivencias y corrupción. Participa en el debate el propio presidente del gobierno, José Canalejas y se descubre a través de los discursos situaciones ilegales. «Hoy en Barcelona se juega, hoy en Madrid se juega. Si quiere su Señoría que los dos tomemos un coche y vayamos a La Peña, al Casino de Madrid, al Círculo de Bellas Artes, al Círculo Militar y a otros, tendrá su Señoría que denunciar el juego conmigo, y es escandaloso que en todas partes, no sólo se falte a la ley, no sólo se esté públicamente jugando, sino que haya un Estado de irritante desigualdad que concede un monopolio a determinados empresarios, que parece que son, o se supone que son, amigos políticos [...] (Soriano a Canalejas, 30 de mayo de 1912, X, p. 3418)» ${ }^{9}$.

Y también destaca el binomio formado por prohibición-reglamentación ${ }^{10}$ en esta materia, donde la relación juego y derecho se estrecha notablemente. Entendiendo por juego, el contrato en virtud del cual se arriesga la adquisición o la pérdida de un valor económico, haciéndola depender de un suceso incierto ${ }^{11}$.

ilustres, fomentando, a la vez, la ociosidad y la relajación de las costumbres en todos aquellos (hombres y mujeres) que los practicaban. Así lo demuestran los innumerables bandos que durante tres siglos de coloniaje, se publicaron para combatir dichos juegos:

"Las (desgracias) que ocasiona en esta capital el abominable vicio de toda clase de juegos de envite son bien constantes y notorias [...] sin que las penas de las Leyes, los reiterados vandos prohibitivos, los exemplares hechos, ni aun la misma experiencia de estas funestas resultas, hayan bastado a remediar tan detestable vicio".

El juego fue por tanto, la gran plaga social. Mal social que sus gobernantes consideraban más peligrosos que otros muchos, cuando se hacen eco de estas palabras del Barón de Bielfield:

"Las inundaciones y los incendios son plagas que devoran de un golpe los bienes de los ciudadanos; pero hay otros males y otros vicios en el estado o en la república que, por ser más lentos, más sordos y más imperceptibles, no arruinan menos las fortunas de los particulares, y que un sabio gobierno debe por consecuencia prevenirlos. Entre éstos cuentas los juegos de suerte"».

9 Vide Mariano Peset Reig, «Breve historia de los impuestos sobre juegos», Palau, 14, (1987), p. 7.

${ }^{10}$ Vide María Lourdes Ramis Rebassa, Régimen jurídico del juego, Marcial Pons, Madrid, 1992, pp. 39-50, donde estudia la evolución histórica de los Códigos Penales sobre el particular.

${ }^{11}$ Vide Juan García Pesarrodona, Régimen jurídico-administrativo de las asociaciones, o.c., p. 157. 
Un largo camino que finaliza con la despenalización que se justifica en el Preámbulo del Decreto-Ley 16/1977, de 25 de febrero, por el que se regulan los aspectos penales, administrativos y fiscales de los juegos de suerte, envite o azar y apuestas ${ }^{12,}{ }^{13}$. Hasta ese momento, los únicos juegos de azar autorizados eran la lotería, las rifas y tómbolas, las quinielas y los sorteos de la Organización Nacional de Ciegos.

Y todo ello teniendo presente que a lo largo de la historia, el Derecho ha adoptado ante el juego tres posiciones: ignorancia del hecho social del juego ${ }^{14}$, prohibición del juego ${ }^{15}$, o una posición intermedia entre las dos alternativas citadas anteriormente. En términos generales, el legislador reconoce la existencia del juego, considera que el mismo puede producir efectos perniciosos, pero estima que el juego es una realidad social cuya desaparición total es poco menos que imposible. Ante ello, prefiere reglamentarlo y paliar así, en lo posible, los efectos perniciosos que le reconoce. En este supuesto controla la práctica de los juegos autorizados o permitidos y penaliza tan sólo las manifestaciones de este fenómeno que la sociedad repudia abiertamente, bien porque figuran asociadas a otras formas de criminalidad, más o menos encubiertas, o bien porque pueden producir trastornos serios en el orden público, que todas las sociedades regidas por el sistema político-social que sea, han considerado siempre que deben preservarse ${ }^{16}$.

\footnotetext{
12 Vide: Real Decreto 444/1977, de 11 de marzo, por el que se dictan normas complementarias del Real Decreto-Ley 16/1977, de 25 de febrero, por el que se regulan los aspectos penales, administrativos y fiscales de los juegos de suerte, envite o azar y de las apuestas; Real Decreto 2709/1978, de 14 de octubre, por el que se modifica parcialmente el Real Decreto 444/1977; Orden de 9 de octubre de 1979, por la que se aprueba la versión definitiva del Catálogo de Juegos autorizados.

13 Vide Real Decreto 2490/1978, de 29 de septiembre, del Ministerio de Hacienda (BOE de 26 de octubre, núm. 256), por el que se establece la distribución de los rendimientos de la tasa sobre los juegos de azar en 1978, art. 2: «[...]. $1^{\text {a }}$. El cincuenta por ciento para financiar las acciones de asistencia, recuperación e integración de los minusválidos físicos y sensoriales, las de asistencia social a favor de la tercera edad, así como las correspondientes a la puesta en funcionamiento del Plan Nacional de Prevención de la Subnormalidad y las actividades de asistencia, recuperación e integración social de los subnormales, a cargo del Ministerio de Sanidad y Seguridad Social, con la consiguiente asignación presupuestaria».
}

14 Vide Johan Huizinga, Homo ludens, sexta reimpresión, Alianza Editorial, Madrid, 1996, p. 7: «Cuando se vio claro que la designación de homo sapiens no convenía tanto a nuestra especie como se había creído en un principio porque, a fin de cuentas, no somos tan razonables como gustaba de creer el siglo XVIII en su ingenuo optimismo, se le adjuntó la de homo faber. Pero este nombre es todavía menos adecuado, porque podría aplicarse también a muchos animales el calificativo de faber. Ahora bien, lo que ocurre con el fabricar sucede con el jugar: muchos animales juegan. Sin embargo, me parece que el nombre de homo ludens, el hombre que juega, expresa una función tan esencial como la de fabricar, y merece, por tanto, ocupar su lugar junto al de homo faber». Vide CENTRO DE INVESTIGACIONES SociológiCAs, «Los españoles y la lotería», Revista Española de Investigaciones Sociológicas, 5, (1979), pp. 289-310.

15 Vide Orden de 6 de febrero de 1978, del Ministerio del Interior (BOE de 17 de febrero, núm. 41), por la que se crea la brigada especial del juego, constituida por una Jefatura Central y cinco Jefaturas de Zona, para actuar en todo el territorio nacional, integrada orgánicamente en la Comisaría General de Seguridad y Orden Público de la Dirección General de Seguridad (art. 1).

16 Vide Comisión Nacional del Juego (Ministerio del InTerior), Libro blanco del juego, Madrid, 1986, p. 21. Vide Miguel OLmeda DíAZ, «La tributación sobre el juego: paternalismo y afectación», Palau, 14, (1987), pp. 59-60, donde señala las características del juego. 
LA COMERCIALIZACIÓN DE LOS JUEGOS DE LA ONCE Y SU INCIDENCIA...

En nuestro país, el juego constituye un sector enormemente heterogéneo, pero, a grandes rasgos, podemos afirmar que está articulado en torno a dos bloques generales:

Los realizados para financiar actividades benéficas o humanitarias. Aquí entrarían los gestionados por la entidad pública empresarial «Loterías y Apuestas del Estado» (LAE), la Lotería Nacional, las denominadas apuestas deportivo-benéficas. También entran en este bloque los gestionados por entidades para remunerar actividades de fin social, como los sorteos de la Cruz Roja o de la propia ONCE. Todos estos sorteos son los de mayor tradición, pues históricamente fueron los primeros en comenzar a operar.

El segundo bloque lo constituyen los juegos, todos ellos del sector privado, que tienen como único fin el lucro empresarial: máquinas tragaperras, bingos, casinos, etc. Ostentan una extraordinaria variedad de técnicas, mecánicas y lugares de juego.

Los juegos que no forman parte de LAE, dependen o están tutelados por el Ministerio del Interior, a través de la Comisión Nacional del Juego, aunque algunas actividades se encuentran trasferidas como competencias propias en ciertas Comunidades Autónomas ${ }^{17,}{ }^{18}$.

\section{La disyuntiva competencial: Estado versus Comunidades Autónomas ${ }^{19}$}

Realizar actividades de organización o explotación de juegos, careciendo de las autorizaciones oportunas, o la modificación unilateral de cualquiera de las condiciones, en virtud de las cuales se concedieron las preceptivas autorizaciones, está penalizado. En 1987, el Ministerio de Economía y Hacien-

17 Vide Antón Álvarez RuIz, La función social de la publicidad de la ONCE, Escuela Libre Editorial, Madrid, 2003, pp. 71-72. Vide Angel Alcaide Inchausti y Fátima AlCaide Arenales, «Fiscalidad del juego en España», Hacienda Pública Española, 93, (1985), pp. 301-310.

18 Vide: Ley 15/1984, de 20 de marzo, de Cataluña, por la que se regulan los juegos de suerte, envite o azar (BOE de 4 de mayo, núm. 107); Ley 14/1985, de 23 de octubre, de Galicia, por la que se regulan los juegos y apuestas (BOE de 7 de marzo de 1986, núm. 57); Ley 6/1985, de 30 de diciembre, de Canarias, por la que se regulan los juegos y apuestas (BOE de 13 de marzo, núm. 62); Ley 2/1986, de 19 de abril, de Andalucía, por la que se regulan los juegos y apuestas (BOE de 3 de junio, núm. 132); Ley 6/1998, de 18 de junio, de Extremadura, normas reguladoras del juego (BOE de 13 de agosto, núm. 193); Ley 6/1999, de 26 de marzo, de Canarias, normas reguladoras de juegos y apuestas (BOE de 23 de abril, núm. 97); Ley 4/1999, de 31 de marzo, de Castilla-La Mancha, normas reguladoras del juego (BOE de 25 de mayo, núm. 124); Ley 2/2000, de 28 de junio, de Aragón, normas reguladoras del juego (BOE de 27 de julio del 2000, núm. 179), modificada por la Ley 3/2004, de 22 de junio (B.O. Aragón de 14 de julio, núm. 82); Ley 3/2001, de 4 de mayo, de Asturias, normas reguladoras del juego y apuestas (BOE de 26 de junio, núm. 110); Ley 6/2001, de 3 de julio, de Madrid, normas reguladoras del juego (BOE de 27 de julio, núm. 179).

19 Vide Roberto Garvia Soto, La organización nacional de ciegos. Un estudio institucional, Centro de Estudios Avanzados en Ciencias Sociales, Madrid, 1993, p. 201, nota 43. 
da promulgó el Real Decreto-Ley de 3 de julio de 1987 (BOE de 4 de julio), del que merece la pena destacar:

«La normativa actualmente vigente en materia de ordenación del juego arranca del Real Decreto-Ley n ${ }^{\circ} 16$ de 25 de febrero de 1977, por el que se despenalizaba y sometía a tributación el mismo, y se prolonga en un centenar largo de disposiciones de diverso rango, que contienen, a su vez, el régimen sancionador del juego. La sentencia del Tribunal Constitucional del 7 de abril de 1987 declaró no ajustadas a la Constitución aquellas sanciones administrativas que carecían de soporte legal. Como quiera que el régimen sancionador en materia de juego está en la actualidad regulado por normas reglamentarias, algunas de ellas, incluso preconstitucionales, y dado que la elaboración de una próxima Ley de juego impone un largo plazo de trámite y aplaza la regulación de los aspectos sancionadores de las actividades de juego, es preciso acudir al procedimiento extraordinario del Real Decreto-Ley con el objeto de cubrir el vacío legal que pudiera producirse y en garantía de los derechos de los ciudadanos. En su virtud, con el informe favorable de la Comisión Nacional del Juego, previo acuerdo del Consejo de Ministros en su reunión del 3 de julio de 1987, en uso de la facultad prevista en el artículo 86 de la Constitución de 1978 [...], dispongo:

Artículo $1^{\circ}$. Objeto y ámbito del Real Decreto-Ley:

1. El objeto del presente Real Decreto-Ley es la regulación de la potestad sancionadora de la Administración Pública en materia de juegos de suerte, envite o azar. [...].

Artículo $2^{\circ}$. Infracciones muy graves. Son infracciones muy graves:

a) Realizar actividades de organización o explotación de juegos, careciendo de las autorizaciones, inscripciones o guías de circulación y con incumplimiento de los requisitos y condiciones establecidas en las mismas; así como la organización o explotación de los juegos en locales o recintos no autorizados o por personas no autorizadas.

b) La modificación unilateral de cualquiera de las condiciones, en virtud de las cuales se concedieron las preceptivas autorizaciones. [...].

e) El fomento y la práctica de juegos y/o apuestas al margen de las normas establecidas o autorizaciones concedidas. [...].

Artículo $3^{\circ}$. Infracciones graves. Son infracciones graves:

a) No llevar los libros de contabilidad exigidos o hacerlo incorrectamente. [...].

c) Efectuar publicidad de los juegos de azar o de los establecimientos en los que éstos se practiquen sin la debida autorización, o al margen de los límites fijados en la misma. $[\ldots] »$.

No es objeto de este trabajo efectuar un análisis profundo sobre las competencias de las respectivas Administraciones sobre el juego ${ }^{20}$. Sin embargo, sí debo poner de manifiesto que se trata de una materia que de modo recurrente propicia nuevas situaciones conflictivas. Buen ejemplo de esta afirmación lo constituye la Ley de Acompañamiento a los Presupuestos para

${ }^{20}$ Vide José Manuel Sala Arquer, «Liberalización del monopolio de loterías y competencias sobre el juego», REDA, 120, (2003), pp. 520-524. 
LA COMERCIALIZACIÓN DE LOS JUEGOS DE LA ONCE Y SU INCIDENCIA...

2002, Ley 24/2001, de 27 de diciembre, de medidas fiscales, administrativas y del orden social, disp. adic. vigésima:

«Corresponde al Estado, a través del Ministerio de Hacienda y, concretamente de la Entidad Pública Empresarial Loterías y Apuestas del Estado, ejercer la competencia, de conformidad con la normativa vigente, para la autorización del desarrollo de todo tipo de apuestas, cualquiera que sea el soporte de las mismas, boletos, medios informáticos o telemáticos, siempre que su ámbito de desarrollo, aplicación, celebración o comercialización abarque el territorio nacional o exceda de los límites de una concreta Comunidad Autónoma.

Se autoriza al Ministerio de Hacienda para dictar cuantas disposiciones de desarrollo fueran necesarias para el mejor cumplimiento de lo previsto en la presente disposición».

Donde a juicio de determinados sectores doctrinales, quizás se pueda vislumbrar una extralimitación de las competencias estatales sobre el juego.

La STC 52/1988, de 24 de marzo, F.J. $5^{\circ}$ estableció que la competencia sobre el juego ${ }^{21}$ no permite a una Administración autonómica incluir o excluir del catálogo de juegos autorizados aquellos que se determinen no en función de sus características propias, sino únicamente por referencia a sus organizadores, en cuanto que la identidad de éstos no puede implicar forzosamente una atribución competencial a la misma ${ }^{22}$.

El régimen jurídico de la competencia estatal y autonómica en materia de loterías ${ }^{23}$ ha sido abordado —entre otras- por la STC 163/1994, de 26 de mayo (F.J.) ${ }^{24}$ :

${ }^{21}$ Vide Alejandro NiETo GARCíA, «Competencias estatales y autonómicas en materia de casinos, juegos y apuestas», en AA.VV., Actualidad y perspectivas del Derecho Público a finales del $S$. XX, Tomo I, Madrid, 1992, pp. 726-727, donde explica magistralmente —como siempre— que, asunción de competencias y transferencias de servicios, son dos cuestiones distintas.

${ }^{22}$ Vide Leopoldo Pons Albentosa, «La tributación del juego en el marco autonómico. Incidencia impositiva y política tributaria», Palau, 14, (1987), pp. 45-46.

${ }^{23}$ La Sentencia del Tribunal Constitucional núm. 164/1994 (Pleno), de 26 de mayo, Ar. 164, ha determinado el sistema español de distribución de competencias en materia de juego, en los siguientes términos (F.J.):

«4. El sistema constitucional de distribución de competencias en materia de juego entre el Estado y las Comunidades Autónomas ha sido objeto de examen en la sentencia dictada, en el conflicto positivo de competencias núm. 957/1985 (STC 163/1994), a cuya fundamentación por tanto procede ahora referirse. Allí, en fundamentos que ahora resumimos, se dice lo que sigue:

A pesar de la falta de mención expresa en los arts. 148.1 y 149.1 CE al juego, sin embargo, esta materia, en el sistema constitucional de distribución de competencias entre el Estado y las Comunidades Autónomas, ha sido atribuida a éstas bajo el genérico y uniforme título competencial de «casinos, juegos y apuestas, con exclusión de las Apuestas Mutuas Deportivo-Benéficas» en la mayoría de los Estatutos de Autonomía, si bien con diferente cualidad y alcance. Por ello, de acuerdo con el art. 149.3 $\mathrm{CE}$, dado que el art. 149.1 CE no reserva al Estado competencia alguna bajo el enunciado de «casinos, juegos y apuestas», puede afirmarse la competencia exclusiva que las Comunidades Autónomas litigantes han asumido en la materia, con la salvedad expresamente establecida en sus respectivos Estatutos de Autonomía; y que esta competencia comprende, con la excepción ya apuntada, la de organizar y autorizar la celebración de juegos en el territorio de la Comunidad Autónoma. 
REALA 300-301 (ENERO-AGOSTO, 2006)

\begin{abstract}
No obstante, ni el silencio del art. 149.1 CE respecto al juego, ni el hecho de que los Estatutos de Autonomía de algunas Comunidades Autónomas califiquen de exclusiva la competencia autonómica pueden interpretarse sin más como determinantes de un total desapoderamiento del Estado en la materia. En cuanto al contenido discutido en los presentes conflictos, en los que el debate gira en torno a si el Estado dispone de competencia para organizar y explotar una lotería de ámbito nacional, no puede desconocerse que teniendo incluso un tratamiento fiscal algunos juegos implantados en todo el territorio nacional, sobre el juego también recae la competencia que al Estado reserva el art. 149.1.14 CE en materia de Hacienda General. Y en virtud de este título compete al Estado la gestión y explotación de la Lotería Nacional por su naturaleza de recurso ordinario de la Hacienda estatal y monopolio del Estado, en tanto en cuanto generador de derechos y obligaciones de contenido económico cuya titularidad a aquélla corresponde [art. 1 Decreto 23 de marzo de 1956, por el que se aprueba la Instrucción General de Loterías; arts. 29 de la Ley General Presupuestaria 11/1977, de 4 de enero, y del Real Decreto Legislativo 109/1988, de 23 de septiembre, por el que se aprueba el texto refundido de dicha Ley].
\end{abstract}

En razón del citado monopolio fiscal, correspondía a la Administración del Estado la gestión y explotación del juego de la lotería en todo el territorio nacional, lo que implicaba, en virtud del meritado régimen monopolístico sobre dicho juego de azar, la prohibición de loterías, sorteos, rifas, apuestas y otras modalidades similares de juego sin la autorización de la Administración del Estado, procediendo, pues, los rendimientos que el Tesoro obtenía del citado monopolio, de la gestión y explotación del juego de la lotería y también del gravamen sobre las autorizaciones administrativas para la organización por los particulares de aquellos juegos. La aprobación de los Estatutos de Autonomía atribuyendo a determinadas Comunidades Autónomas competencia exclusiva en materia de juego y apuestas para organizar y autorizar su celebración en el respectivo territorio, no sustrae a la competencia estatal la de gestionar en todo el territorio nacional el monopolio de la Lotería Nacional, configurado como fuente o recurso económico de la Hacienda del Estado, pues la prescripción del art. 149.1.14 CE engloba necesariamente la competencia sobre lo que constituye una fuente de ingresos no tributarios asumida como explotación de un monopolio fiscal, sin perjuicio de la competencia de algunas Comunidades Autónomas en materia de juego.

El concepto de juego de la Lotería y su explotación como recurso de la Hacienda del Estado incluido en el art. 149.1.14 CE no puede quedar referido únicamente a la específica modalidad con la que aquél aparece configurado en la Instrucción General de Loterías de 23 de marzo de 1956. La lotería, como antes decimos, en las diversas modalidades en las que ha sido organizado por la Administración históricamente ha constituido desde su instauración una renta de la Hacienda Pública llegando a coexistir distintas modalidades de loterías, como la legislación positiva demuestra; pero además, la aceptación de aquel razonamiento reduccionista supondría confundir lo que jurídica e institucionalmente se configura como una fuente de ingresos no tributarios directamente explotada por la Hacienda estatal, con una mera modalidad de dicho juego, excluyéndose así la competencia del Estado, ex art. 149.1.14 CE, para gestionar y explotar lo que es un recurso o fuente de su Hacienda.

Por último, no siendo el mismo el nivel de competencias que sobre el juego tienen atribuido las distintas Comunidades Autónomas, tampoco es uniforme el que corresponde al Estado en la materia. Por ello, a las Comunidades que, como las que han promovido los conflictos de competencia objeto de este proceso constitucional, han asumido competencias exclusivas en materia de casinos, juegos y apuestas, les corresponden en su ámbito territorial las competencias no reservadas al Estado por el enunciado del art. 149.1.14 CE y las no excluidas expresamente de la atribución autonómica por sus respectivos Estatutos de Autonomía.

5. [...]. Las disposiciones y actos impugnados tienen por objeto, pues, la organización (o más bien reinstauración) y puesta en explotación por el Estado, a través del Organismo Nacional de Loterías y Apuestas, de una lotería de ámbito nacional en la modalidad conocida por Lotería Primitiva o de Números, que presenta en su sistema de sorteos o concursos una doble variante (sobre la misma modalidad) y cuyos rendimientos, detraídos de la recaudación obtenida los porcentajes destinados a premios y gastos de administración, al integrarse en el Tesoro Público forman parte de los ingresos del Estado y constituyen, por tanto, derechos económicos de su Hacienda. Conforme con la doctrina antes reseñada, las impugnaciones de las disposiciones y actos controvertidos no pueden ser acogidas, pues éstos no invaden ni menoscaban las competencias que en materia de juego han asumido las Comunidades Autónomas impugnantes por estar reservada a la competencia del Estado, ex art. 149.1.14 CE, en razón de su naturaleza de fuente o recurso de la Hacienda estatal, el monopolio de la Lotería Nacional; correspondiéndole, pues, la facultad de organizar loterías de ámbito nacional en sus distintas modalidades».

${ }^{24}$ Vide Francisco L. HeRnández GonZÁLEZ, La regulación de los juegos de azar, Tecnos, Madrid, 1996, pp. 69-70. 
LA COMERCIALIZACIÓN DE LOS JUEGOS DE LA ONCE Y SU INCIDENCIA...

«3. Notorio es que en la fijación por la Constitución de las materias sobre las que las Comunidades Autónomas pueden asumir estatutariamente competencias (art. 148.1 CE), o sobre las que se reservan al Estado —indisponibles, por ello, para los Estatutos de Autonomía (art. 149.1 CE)—, no existe ninguna mención expresa en relación al juego en general, como tampoco se hace en dichos Estatutos; pero en éstos, con la única excepción de la Comunidad Autónoma de Madrid, aparece con el singular y uniforme título de «casinos, juegos y apuestas, con exclusión de las Apuestas Mutuas Deportivo-Benéficas», la atribución a las correspondientes Comunidades Autónomas de competencias de diferente cualidad y alcance, pues a algunas, entre ellas Cataluña, se les atribuye competencia exclusiva [arts. 10.35 EAPV; 9.32 EAC; 27.27 EAG; 13.33 de Andalucía; 31.31 EACV; 44.16 LORAFNA y 10.10 EAIB], a otras la ejecución de la legislación del Estado [art. 36.2 d) EAAr]; y, finalmente, respecto a otras se prevé una futura asunción de competencias cuando se activen los procedimientos que lo permitan [arts. $13.1 \mathrm{c}$ ) EAAS; $25.1 \mathrm{c}$ ) EACTB; 11.1 e) EALR; 13.1 b) EARM; 35.1 c) EACM; 34 a) EACan; 10.1 b) EAE; 29.1.18 EACyL].

Por lo tanto, con arreglo a la cláusula del art. 149.3 CE, según la cual «las materias no atribuidas expresamente al Estado por esta Constitución podrán corresponder a las Comunidades Autónomas en virtud de sus respectivos Estatutos..», y dado que en el art. 149.1 CE no se reserva al Estado competencia alguna bajo el enunciado de «casinos, juegos y apuestas», cabe afirmar que corresponde a la Generalidad de Cataluña, de acuerdo con el art. 9.32 EAC, la competencia exclusiva sobre los casinos, juegos y apuestas, excepto las Apuestas Mutuas Deportivo-Benéficas [STC 52/ 1988), fundamento jurídico $4 .^{\circ}$ ], y que esta competencia comprende la de organizar y autorizar la celebración de juegos en el territorio de la Comunidad Autónoma.

Ahora bien, ni el silencio del art. 149.1 CE respecto al juego ni el hecho de que los Estatutos de Autonomía de algunas Comunidades Autónomas, entre ellas el de Cataluña, califiquen de exclusiva la competencia autonómica (excepto las Apuestas $\mathrm{Mu}-$ tuas Deportivo-Benéficas) puede interpretarse como equivalente a un total desapoderamiento del Estado, pues ciertas materias y actividades que bajo otros enunciados el art. 149.1 CE reserva a aquél se encuentran estrechamente ligadas con el juego. Como reiteradamente tiene declarado este Tribunal, la calificación jurídica y el alcance de las competencias de las Comunidades Autónomas no puede hacerse derivar únicamente de una lectura aislada de la denominación que reciben en los textos estatutarios sino de una interpretación sistemática de todo el bloque de la constitucionalidad, dentro del cual la Constitución «conserva intacta su fuerza normativa dominante como lex superior de todo el ordenamiento, fuerza normativa que no se agota ni disminuye con la promulgación de los Estatutos de Autonomía, cuyos preceptos, por más que califiquen como exclusiva la competencia asumida ratione materiae, no pueden oponerse a las normas constitucionales que, en su caso, reconozcan al Estado títulos competenciales sobre esa misma materia» (STC 20/1988). [...]».

La misma STC 164/1994, de 26 de mayo, recoge un voto particular formulado por el Magistrado don Carles Vives Pi-Sunyer, donde se pronuncia sobre la atribución competencial estatal y donde plantea que la capacidad de expansión de la competencia estatal sobre la Hacienda General entendida como 
la entiende la sentencia y la posibilidad de que desde la misma se llegue a subvertir en la práctica el orden de competencias diseñado en el bloque de la constitucionalidad no requiere - a su entender-, grandes esfuerzos demostrativos.

«3. En la sentencia se atribuye al Estado la competencia para organizar la Lotería Primitiva en todo el territorio español en virtud del título competencial de Hacienda General del art. 149.1.14 CE. No comparto esta calificación competencial. El hecho de que la Lotería Primitiva, único tipo de lotería cuestionado por la recurrente, se configure como fuente de ingresos públicos y monopolio fiscal no permite incluir en ese ámbito la organización y gestión de este juego de apuestas. Así como este Tribunal ha reiterado que la potestad de gasto no puede convertirse en título competencial, tampoco puede atribuirse esta condición a lo que para simplificar podríamos denominar potestad de ingreso. De aceptarse esta tesis el Estado podría reservarse la regulación e incluso la ejecución en cualquier materia, prescindiendo de si están o no atribuidas a las Comunidades Autónomas, mediante el cómodo expediente de convertir dicha actividad en fuente de ingresos públicos estatales. Aun admitiendo una amplísima posibilidad de que desde el título de Hacienda General puedan afectarse los más diversos ámbitos materiales, esa afectación deberá limitarse, por lo que aquí interesa, a los aspectos relativos a la recaudación de ingresos públicos, pero no puede atraer de forma indiscriminada toda la organización y gestión de las actividades que constituyen el contenido y objeto de otras materias competenciales, por el mero hecho de que el Estado haya decidido convertirlas en fuente de ingresos propios. La capacidad de expansión de la competencia estatal sobre la Hacienda General entendida como la entiende la sentencia y la posibilidad de que desde la misma se llegue a subvertir en la práctica el orden de competencias diseñado en el bloque de la constitucionalidad no requiere, a mi entender, grandes esfuerzos demostrativos. [...]».

Y sobre la dificultad de títulos competenciales en el mismo territorio, manifiesta que no comparte «la duplicidad de títulos competenciales que se consagra en la sentencia, en la que se afirma que la Comunidad Autónoma también puede realizar el mismo tipo de actividad dentro de su ámbito territorial. Nuestro ordenamiento jurídico, a diferencia de lo que sucede en los de otros Estados compuestos, ha optado por un sistema de distribución de competencias basado en el reparto de actividades entre entes, no por un modelo concurrencial o de duplicidad. Pues bien, la primera y fundamental consecuencia que deriva de esta opción constitucional es la de que desde dos títulos competenciales diferentes - en este caso, Hacienda General y juego- no puede realizarse exactamente el mismo tipo de funciones, sobre el mismo tipo de actividades» ${ }^{25}$.

\footnotetext{
${ }_{25}$ Vide STC 164/1994, de 26 de mayo, voto particular formulado por el magistrado don Carles Vives Pi-Sunyer: «[...]. Pues bien, la primera y fundamental consecuencia que deriva de esta opción constitucional es la de que desde dos títulos competenciales diferentes —en este caso, Hacienda General y juego - no puede realizarse exactamente el mismo tipo de funciones, sobre el mismo tipo de activida-
} 


\title{
III. EL CUPÓN DE LA ORGANIZACIÓN NACIONAL DE CIEGOS ESPAÑOLES
}

\section{Aproximación conceptual}

La primera vez que se empleó el nombre de cupón relacionado con loterías benéficas para ciegos fue en 1933, cuando en Madrid surgió el cupón del chiquilín: rifa combinada con cromos coleccionables en un álbum. Posteriormente, la Sociedad de Ciegos «La Hispalense» de Sevilla, llamó a su lotería Cupón Pro-ciegos, nombre que luego pasó a tener el de la ONCE ${ }^{26}$.

El 8 de mayo de 1939 se considera como el día en el que la ONCE celebró los primeros sorteos del cupón pro-ciegos, pese a que muchas asociaciones que vendían rifas con anterioridad, tras su incorporación a la nueva organización, continuaron haciéndolo hasta que terminaron sus existencias ${ }^{27}$. Tam-

\begin{abstract}
des, coincidiendo ambas en un mismo territorio, aunque una de ellas se extienda a un ámbito más amplio. En nuestro ordenamiento, aceptar el solapamiento de títulos competenciales equivale a desconocer el criterio hermenéutico basado en la presunción de coherencia del legislador, que no puede haber querido decir la misma cosa con términos y conceptos distintos. Tampoco puede admitirse la duplicidad si la competencia de la Comunidad Autónoma para organizar sus propias loterías se basa en la competencia sobre la Hacienda autonómica — cuestión que plantearía problemas de otra índole-. Como luego se razonará, no resulta compatible con el sistema de distribución de competencias establecido en el bloque de la constitucionalidad defender la duplicidad de actividades atendiendo al diferente alcance territorial de la actividad ejercida por el Estado y por una Comunidad Autónoma a partir de un mismo título competencial.
\end{abstract}

En el plano práctico, esta duplicidad o solapamiento de títulos, como pone de relieve la recurrente, no es en absoluto inocua ya que la existencia de una Lotería Primitiva de ámbito estatal en el territorio de la Comunidad Autónoma - existencia que ha ido incrementándose con la ampliación de las modalidades de Loto Primitiva, Bono-Loto, El Gordo de la Primitiva, hasta establecer sorteos prácticamente diarios- supone que una parte importante del monto, siempre limitado y no elástico, de recursos económicos destinados al juego en ese territorio se dirigen a la Lotería estatal en detrimento de la autonómica ya que el superior volumen de ingresos de la primera lleva a que también los premios sean mayores y consiguientemente atraigan más a los jugadores.

En definitiva, atribuir al Estado la posibilidad de organizar y gestionar la Lotería Primitiva en el territorio autonómico supone vulnerar el sistema de distribución de competencias establecido en el bloque de la constitucionalidad y menoscabar la competencia autonómica exclusiva en la materia de juegos y apuestas, ya que la Comunidad Autónoma deja de ser el único sujeto que puede definir la política sobre el juego en su ámbito territorial. Esta conclusión no excluye la posibilidad de organizar la Lotería Primitiva en un ámbito supraautonómico, pero sí requiere que en estos supuestos, la organización sea fruto de mecanismos de cooperación y que, en cualquier caso, la decisión última sobre la celebración de los mismos en los distintos territorios autonómicos corresponde a las respectivas Comunidades Autónomas con competencias en la materia».

${ }^{26}$ Vide ONCE, Historia del cupón, ONCE, Madrid, 1987, sin paginar.

27 Ibídem. Respecto al precio del cupón señala: «Como indicamos anteriormente, el Cupón Pro-Ciegos, entre 1939 y 1983, no varió su estructura, diseño, etc. Durante estos años tan sólo sufrió variaciones el precio:

- El Cupón se comenzó a vender a 10 céntimos.

— El 1 de septiembre de 1950 se elevó el precio a 20 céntimos.

- 5 años después, el 21 de septiembre de 1955, se establecía éste en 50 céntimos. 
bién debo señalar que en muchas partes de Levante, entre Valencia y Almería, existe la tradición de dar a cada cifra de las dos últimas del cupón un nombre diferente; así habitualmente, compradores y vendedores los denominaban por estos motes y no por el número correspondiente. No se sabe cuándo comenzó esta costumbre, pero, en todo caso, es anterior a la creación de la ONCE, pues ya era utilizado en diferentes rifas surgidas en las zonas levantinas ${ }^{28}$.

Tal y como establecía el Reglamento de la Organización Nacional de Ciegos (Orden del Ministerio de la Gobernación de 28 de octubre de 1939), art. 14 , se ponía a la venta el denominado «cupón pro-ciegos», con carácter voluntario, como forma exclusiva de ingresos para los afiliados a la misma.

El cupón prociegos es el documento contractual legalmente emitido en el que se establecen reciprocamente las obligaciones de las partes, que consisten fundamentalmente en que el cliente comprador del cupón pro-ciegos paga un precio cierto por el cupón unidad y la ONCE se compromete a dar a cambio una cantidad de dinero, conforme a la escala de premios preestablecida, en función de un hecho incierto o aleatorio, consistente en la coinci-

- 1 peseta el 2 de enero de 1958.

- Justamente 6 años más tarde, en 1964, el Cupón comenzó a costar el doble, 2 pesetas.

- 5 pesetas a partir del 1 de octubre de 1969.

- En el año 76, el 2 de enero, el Cupón comenzó a venderse a 10 pesetas.

- 25 pesetas desde el 1 de mayo de 1979».

Vide ONCE, 65 años de historia, ONCE, Madrid, 2004, p 73, donde detalla la evolución del premio del cupón y del premio de las dos últimas cifras (las cantidades que aparecen guardan también este orden): «Del 8 de mayo de 1939 al 31 de agosto de 1950: 25 pts; 2,50 pts. Del 1 de septiembre de 1950 al 20 de septiembre de 1955: 50 pts; 5 pts. Del 21 de septiembre de 1955 al 31 de diciembre de 1957: 125 pts; 12,50 pts. Del 2 de enero de 1958 al 31 de diciembre de 1963: 250 pts; 25 pts. Del 2 de enero de 1964 al 30 de septiembre de 1969: 500 pts; 50 pts. Del 1 de octubre de 1969 hasta el 31 de diciembre de 1975: 1.250 pts; 125 pts. Del 2 de enero de 1976 al 30 de abril de 1979: 2.500 pts; 250 pts. Del 2 de mayo de 1979 al 31 de diciembre de 1983: 6.250 pts; 625 pts».

${ }_{28}$ Vide ONCE, Historia del cupón, ONCE, Madrid, 1987, sin paginar. En este trabajo se relaciona el nombre que el pueblo alicantino dio a los números: «1: El Galán; 2: El Sol; 3: El Niño; 4: La Cama; 5: La Punta; 6: El Corazón; 7: La Luna; 8: La Dama; 9: El Arpa; 10: La Rosa; 11: El Clavel; 12: La Talega; 13: El Verde; 14: Las Cerezas; 15: La Uva; 16: La Guitarra; 17: El Navío; 18: El Ramo; 19: San José; 20: España; 21: Francia; 22: La Manzana; 23: El Melón; 24: La Galera; 25: El Cañón; 26: El pollo; 27: La Pajarita; 28: Alicante; 29: Aragón; 30: El León; 31: El Caballo; 32: La Bomba; 33: La Torre; 34: El Pato; 35: El Infierno; 36: La Ensalada; 37: La Espada y Daga; 38: El Perro; 39: El Toro; 40: La Campana; 41: El Negro; 42: La Estrella; 43: La Corona; 44: El Clarín; 45: El Tambor; 46: El Sombrero; 47: El Mundo; 48: La Negra; 49: La Breva; 50: El Cartucho; 51: La Cabra; 52: El Tomate; 53: El Pimiento; 54: La Mala Noche; 55: Los Gallegos; 56: La Lechuga; 57: La Zanahoria; 58: Los Limones; 59: El Canario; 60: La Abuela; 61: La Pipa; 62: El Piojoso; 63: La Paella; 64: La Casa; 65: La Pelea; 66: Las Monjas; 67: El Fraile; 68: El Rosario; 69: La Mudanza; 70: El Albaricoque; 71: El Maestro; 72: El Higo; 73: El Conejo; 74: La Escalera; 75: El Gato; 76: El Agua; 77: Las Banderas; 78: El Escarabajo; 79: El Marrano; 80: La Lavandera; 81: El Matrimonio; 82: El Orinal; 83: La Dama y el Niño; 84: Casamiento; 85: La Palmera; 86: Mierda; 87: El Pescado; 88: Las Mamas; 89: La Gamba; 90: El Abuelo; 91: El Borracho; 92: El Palomo; 93: La Revolución; 94: La Rata; 95: El Pavo; 96: La Explanada (Paseo principal de Alicante, por lo cual en otras ciudades el 96 es el Parque, La Alameda, etc); 97: La Gallina; 98: El Borrego; 99: La Agonía; 00: La Muerte». 
LA COMERCIALIZACIÓN DE LOS JUEGOS DE LA ONCE Y SU INCIDENCIA...

dencia total o parcial y en el mismo orden de los números contenidos en el cupón, hecho aleatorio que se despeja mediante el instrumento o la fórmula del sorteo celebrado con periodicidad diaria, mensual, anual, etc. ${ }^{29,}{ }^{30}, y$ que supone el medio excepcional de ingresos autorizado y concedido por el Gobierno en monopolio, de la Corporación de Derecho Público ONCE ${ }^{31}$.

Se entiende por cupón emitido por terminal de punto de venta, aquel que se imprime por un agente vendedor en el momento de efectuarse la transacción, utilizando un terminal de punto de venta.

La finalidad esencial de esta modalidad de juego de azar es doble: procurar empleo y atender las necesidades de los afiliados a la Corporación de

${ }_{29}$ Vide Jesús Montoro Martínez, Los ciegos en la historia, Tomo V, ONCE, Madrid, 1998, p. 113. Debo señalar, que desde el 2 de enero de 1984, se estableció en la ONCE un único sorteo para todo el país. También debo destacar que desde el día 5 de octubre de 1985, no se vende cupón de la ONCE en sábado.

${ }^{30}$ Vide Antón Álvarez RuIz, La función social de la publicidad de la ONCE, Escuela Libre Editorial, Madrid, 2003, pp. 73-74, donde explica el brand wheel (rueda de marca) del cupón. Básicamente consiste en una metodología que se aplica a los productos de gran consumo, porque permite conocer con detalle las imágenes y los elementos afectivos que los consumidores asocian a los productos y a las marcas. De esta forma, se utiliza para poder detectar diferencias, a veces muy sutiles, entre marcas y productos técnicamente muy parecidos sobre las que sustentar un posicionamiento competitivo en el mercado. Lo habitual es no aplicar la brand wheel a servicios o marcas del sector terciario (cupón), que no se desenvuelven en mercados tan despersonalizados y competitivos.

La «Brand Wheel» del cupón de la ONCE es la siguiente:

\begin{tabular}{|c|c|c|}
\hline & PRIMARIOS & SECUNDARIOS \\
\hline ATRIBUTOS & $\begin{array}{l}\text { Barata } \\
\text { Fácil de conseguir } \\
\text { Frecuente cotidiana } \\
\text { Popular } \\
\text { Conocida } \\
\text { Sencilla }\end{array}$ & $\begin{array}{l}\text { Gran presencia en medios } \\
\text { Poco tiempo entre apuestas y sorteo }\end{array}$ \\
\hline BENEFICIOS & Cómoda/Fácil de jugar & $\begin{array}{l}\text { Me entero fácilmente del premio } \\
\text { Me entero enseguida del premio } \\
\text { Da para un capricho }\end{array}$ \\
\hline VALORES & Ilusión diaria & $\begin{array}{l}\text { Me siento bien jugando } \\
\text { Contribuyo a una labor social }\end{array}$ \\
\hline $\begin{array}{l}\text { PERSONALIDAD } \\
\text { DE MARCA }\end{array}$ & $\begin{array}{l}\text { Fiable/de confianza } \\
\text { Sociable } \\
\text { Amable } \\
\text { Amistoso } \\
\text { Modesto } \\
\text { Entrañable }\end{array}$ & $\begin{array}{l}\text { Optimista } \\
\text { Dinámico } \\
\text { Moderno } \\
\text { Con humor } \\
\text { Atractivo } \\
\text { Pacífico }\end{array}$ \\
\hline
\end{tabular}

Los datos fueron obtenidos de una conferencia ofrecida por la Dirección de Relaciones Públicas y Publicidad de la ONCE, ofrecida en Madrid, en 1993.

31 Vide: Rafael de Lorenzo GarcíA, «La Organización Nacional de Ciegos Españoles: breve estudio de una Organización singular», en AA.VV., El sector no lucrativo en España, Escuela Libre Editorial, Madrid, 1993, pp. 270-274: «El cupón de la ONCE»; ASV, «Cupón de la ONCE falsificado», Diario El País (versión electrónica), 24-2-1988; EFE, «Detenido un español en la frontera portuguesa con 500.000 cupones falsos de la ONCE», Diario El País (versión electrónica), 24-9-1989. 
Derecho Público creada a tal efecto. Y a pesar de que se preveía su carácter residual, hoy es su recurso fundamental, tal y como ha determinado la STC 171/1998 (Pleno), de 23 de julio (F.J.):

$\ll 5$. Tanto en la norma fundacional como en las que posteriormente han procedido a reordenar la estructura organizativa de la ONCE se ha atendido y se atiende de forma expresa a los recursos económicos de los que dispone la entidad en orden al cumplimiento de los fines de interés público que se le encomiendan. Entre ellos, ya en el Reglamento de 1939 se contemplaba el producto de la implantación y organización por la Sección de Trabajo del denominado «cupón pro-ciegos», calificado como forma «excepcional y exclusiva» de ingresos para los no videntes y, por consiguiente, como fuente de recursos de la ONCE, al que además se confería un carácter residual, en cuanto actividad, ya que la venta del mencionado «cupón pro-ciegos» se preveía que fuera ejercitada por los no videntes «imposibilitados de desempeñar una profesión u oficio especial». Significativo de dicho aspecto resulta el que su implantación y organización se le encomendara, de entre las secciones en las que se estructuraba la ONCE, a la Sección de Trabajo, a quien correspondía la organización y el fomento del trabajo de los invidentes (art. 14 de la Orden del Ministerio de Gobernación de 28 de octubre de 1939). En idénticos términos, como recursos económicos de la entidad vinculados al cumplimiento de los fines que se le atribuyen, aparecen caracterizados en la posterior normativa por la que se procede a reordenar la estructura organizativa de la ONCE los beneficios derivados de la explotación en exclusiva de la venta del "cupón pro-ciegos» [arts. 3 del Real Decreto 1041/1981, de 22 de mayo; 3, b) del Real Decreto 358/1991, de 15 de marzo y 5 de los Estatutos].

Así pues, el denominado «cupón pro-ciegos» aparece estrechamente vinculado, tanto históricamente como en la actualidad, a la decisión estatal de creación de la ONCE y al cumplimiento de los fines de indudable interés público que tiene encomendados, en razón de los cuales se define hoy aquélla como una Corporación de Derecho Público de carácter social, configurándose los rendimientos de aquél como un recurso financiero de una determinada entidad en orden a la satisfacción de los intereses públicos que ha de atender con su actividad respecto a un concreto colectivo de personas, los incapacitados visuales, con notables dificultades de integración, para los cuales la ONCE ha de perseguir la consecución de su autonomía personal y plena integración en la sociedad (art. 2.1 del Real Decreto 358/1991). En otras palabras, la justificación de la concesión que históricamente se ha mantenido, de la explotación del «cupón pro-ciegos», como fuente de recursos financieros de la entidad, no reside sino en la necesidad de dotarle de los medios económicos suficientes para el cumplimiento de los relevantes fines de indudable interés público que ha asumido desde su creación y asume en la actualidad. Medios económicos que arbitró el Estado mediante la autorización de ese sorteo en lugar de asignar una consignación con cargo a su propio presupuesto, constituyendo así una fuente de ingresos de la ONCE que ha sido y sigue siendo el principal recurso financiero de la entidad, soporte, por lo tanto, imprescindible e indispensable para el desempeño de las actividades que realiza tendentes a la satisfacción de los fines de interés público que tiene encomendados y que son su razón de ser y que hace posible el sostenimiento de aquellas actividades y la pervivencia de la propia entidad. Conservando además el 
LA COMERCIALIZACIÓN DE LOS JUEGOS DE LA ONCE Y SU INCIDENCIA...

mismo carácter de actividad de los invidentes que presentaba en el momento de la constitución de la ONCE, constituyendo un medio singular de trabajo reservado a aquéllos o a otras personas afectadas con minusvalías diferentes -más de 21.000 personas- para posibilitar su integración profesional y social.

El sorteo del cupón, también conocido tradicionalmente como "lotería de los ciegos", ha sido y sigue siendo, pues, el medio económico indispensable y esencial para el logro por la Corporación de los referidos fines. [...]».

\section{Naturaleza jurídica}

Los cupones de la ONCE deben catalogarse como títulos al portador ${ }^{32}$, cuyo rendimiento tiene naturaleza de ingreso público y supone el medio económico suficiente para el cumplimiento de los relevantes fines de interés público que ha asumido desde su creación y asume en la actualidad. Así lo

${ }^{32}$ Vide Sentencia del Tribunal Superior de Justicia de Asturias núm. 532/1999 (Sala de lo Contencioso-Administrativo, Sección $1^{\text {a }}$ ), de 29 de junio, Ar. 1868:

\section{«FUNDAMENTOS DE DERECHO}

PRIMERO.- Se impugna por la recurrente la denegación presunta del recurso interpuesto contra la Resolución de la ONCE de 12 de abril de 1996 por la que se le denegaba el pago de 2.500 .000 pesetas correspondientes al premio de un cupón del sorteo del día 30 de enero de dicha anualidad, fundándose dicha impugnación en la manifestación de haber extraviado el cupón identificado con la serie 34 del número 61.452 que había adquirido en el «Bar Baizán» de Gijón junto con otros amigos de una peña que diariamente acude a dicho establecimiento, tal y como éstos pueden acreditar; señalando asimismo que sólo después de iniciado el presente procedimiento pudo percatarse de que el citado cupón había sido abonado en esta Delegación Territorial. Indicándose como fundamentación jurídica el Real Decreto 358/1991 de 15 marzo de 1991 y concordantes.

SEGUNDO.- La señora Letrada de la ONCE se opone a la demanda en base a las alegaciones siguientes: $1^{\circ}$ ) Los cupones de la ONCE se consideran títulos al portador y constituyen el único documento válido para acreditar el premio sin que pueda sustituirse por ningún otro medio; $2^{\circ}$ ) El plazo hábil para cobrar el cupón es de 30 días naturales, habiéndose presentado al cobro tres días antes de la fecha límite en la Agencia de Pola de Siero y de ahí que en un primer momento se indicara al esposo de la recurrente que aún no había sido abonado; $3^{\circ}$ ) Resulta irrelevante que en los cupones figure el número del DNI de los perceptores del premio o que se cobren en un lugar u otro (artículo 13, circular 7/1991); $4^{\circ}$ ) No existe enriquecimiento injusto para la recurrida al haber abonado el importe a quien lo presentó y entregó.

TERCERO.- Los cupones de la ONCE deben catalogarse como títulos al portador dada su similitud con los billetes de la Lotería Nacional por lo que, en principio, resulta inexcusable su presentación para el cobro del premio, tal y como, por otra parte, establece el artículo 13 de la circular 7/1991, y si bien es cierto que el Tribunal Supremo tiene en ocasiones declarado que dicho requisito de la presentación puede sustituirse por otros relevantes medios de prueba que acrediten tanto la legitimidad posesoria del reclamante como la coincidencia absoluta entre el número y fracción del billete premiado (Sentencia del Tribunal Supremo de 3 de marzo de 1989, por todas), ello será siempre sobre la base de que dicho título no haya sido abonado (Sentencia del Tribunal Supremo de 11 de noviembre de 1994), tal y como aquí ha sucedido según se desprende del testimonio del cupón obrante en el recurso en que aparece abonado en Siero en fecha 26 de febrero de 1996, circunstancia ésta que, en su caso, podría dar lugar a que por la recurrente se ejercitaran las acciones correspondientes en la vía oportuna (incluso la penal) mas en forma alguna motivar la anulación de la resolución recaída en vía administrativa que, por las razones apuntadas, ha de estimarse conforme a derecho, sin que se estime, por otra parte, necesaria la práctica para mejor proveer de la testifical propuesta por la recurrente dado que el resultado de la misma nada podría influir en el resultado del recurso, teniendo en cuenta los motivos en base a los que éste se desestima». 
ha establecido la STC 171/1998 (Pleno), de 23 de julio, Ar. 171, en el Fundamento Jurídico 2:

«[...]. Asimismo, en defensa de la constitucionalidad de los preceptos impugnados aduce también la competencia del Estado sobre las bases del régimen jurídico de las Administraciones Públicas (art. 149.1.18 CE) y sobre las fundaciones y asociaciones de carácter benéfico-asistencial y ámbito nacional (art. 9.24 EAC), dado que la ONCE es una entidad de Derecho Público que desarrolla su actividad en todo el territorio del Estado, sometida a la tutela y al protectorado de éste y que explota aquel juego como medio de financiar las actividades que definen y justifican su existencia. En definitiva, tanto el hecho de que los rendimientos de la «Lotería Pro-Ciegos» son ingresos públicos del Estado, como el relativo a la relación de instrumentalidad que dicha lotería tiene respecto a todo el complejo de actividades de la ONCE son factores que, a su juicio, determinan la titularidad competencial del Estado respecto a la citada organización y a la gestión del «cupón pro-ciegos».

Al igual que sucede con la lotería, este contrato manifiesta las características propias de un contrato de adhesión, pues el comprador no tiene más alternativa que pasar por todas y cada una de las condiciones o requisitos que se han establecido. Tales imposiciones se justifican por la propia dinámica del juego, por las cautelas y las condiciones inherentes a la seguridad jurídica propias de una actividad de esta naturaleza. Por todo ello, nunca se coloca al cliente en situación de indefensión, sino todo lo contrario, pues resulta esencial garantizar sus derechos con total transparencia.

\section{Clasificación}

\subsection{Lotería instantánea o presorteada y lotería condicionada a la realización del sorteo}

La lotería instantánea o presorteada consiste en la posibilidad de obtención de un premio establecido en el programa correspondiente, o definido o representado en la tarjeta, boleto o cualquier otro soporte electrónico o telemático empleado para su difusión y que es invisible para el jugador hasta que proceda a su revelado o apertura, a través de los medios previstos en cada producto ${ }^{33}$.

\footnotetext{
${ }_{33}$ Vide Real Decreto 1336/2005, de 11 de noviembre, por el que se autoriza a la Organización Nacional de Ciegos Españoles la explotación de la lotería instantánea o presorteada (BOE de 22 de noviembre, núm. 279): «La Organización Nacional de Ciegos Españoles (ONCE), corporación de derecho público de carácter social, ha desempeñado a lo largo de sus más de 60 años de historia una labor trascendental en la integración y autonomía personal de los ciegos españoles, que con el transcurso de los años se ha ido extendiendo paulatinamente, sobre la base del principio de la solidaridad, a otras personas discapacitadas, por medio de la Fundación ONCE, todo ello dentro de un marco de colaboración con la Administración General del Estado.
} 
LA COMERCIALIZACIÓN DE LOS JUEGOS DE LA ONCE Y SU INCIDENCIA...

Mientras que la fórmula tradicional implica esperar hasta la realización del sorteo previamente anunciado para saber si el boleto en nuestro poder ha sido premiado.

\subsection{Tipos de soporte para el cupón: el cupón preimpreso y el cupón emitido por terminal de punto de venta}

La comercialización del cupón podrá efectuarse mediante dos tipos de soporte: cupones preimpresos y cupones emitidos por terminales de punto de venta.

Los terminales de punto de venta son los terminales móviles facilitados a los vendedores de la ONCE, adaptados para su utilización por personas invidentes o con otro tipo de discapacidades.

\subsection{Formas de comercialización del cupón preimpreso: cupones de un único sorteo y cupones de varios sorteos, también denominados abono semanal}

La comercialización se podrá realizar utilizando dos tipos de producto: cupón que representa participación en un único sorteo y cupón representativo de participaciones en varios sorteos.

\subsection{Formas de comercialización del cupón emitido por terminal de punto de venta}

Serán las siguientes: el cupón para un solo sorteo, el cupón que podrá contener la participación en varios sorteos de los que se celebren en el período máximo de siete días naturales, y el cupón denominado Abono Semanal.

\footnotetext{
Para la consecución de estos fines, la ONCE ha contado tradicionalmente con los ingresos que le ha reportado la comercialización del cupón «prociegos», ingresos que se han dedicado a atender los compromisos sociales de la organización para conseguir el bienestar la integración social de sus afiliados y cumplir el citado compromiso de solidaridad adquirido con otros discapacitados, y que se ha destinado a crear, mantener y mejorar la calidad de los puestos de trabajo y para impulsar la formación de estas personas.
}

La actual evolución de los juegos en España hace preciso dotar a la ONCE de nuevos instrumentos para que esta organización pueda continuar disponiendo de los medios necesarios para el cumplimiento de sus objetivos y fines sociales.

A fin de atender los mencionados compromisos, se entiende necesario que la ONCE comercialice una nueva modalidad de lotería, de ámbito nacional, que satisfaga las preferencias de aquellos jugadores que demandan una lotería de «premio inmediato» o «instantáneo».

En suma, las razones expuestas de preservar tanto la labor social llevada a cabo por la ONCE como la estabilidad en el empleo de las personas que comercializan los juegos que tiene concedidos, unidas a las circunstancias de carácter comercial señaladas, justifican la autorización de la gestión de una lotería «instantánea» o «presorteada» por la ONCE, en todo el territorio nacional y por medio de los vendedores integrados en su plantilla de trabajadores». 


\subsection{Modalidades de comercialización: tipología de juegos ${ }^{34}$}

\subsubsection{Sorteo del cupón de lunes a jueves ${ }^{35}$}

Se determina por parte del Consejo de Protectorado la cantidad máxima de emisión por sorteo, la cantidad destinada a premios, la distribución de premios por emisión y el precio del cupón.

${ }^{34}$ Vide Memoria de la Dirección General de la ONCE, año 2003, importancia relativa de los productos ONCE:

$\begin{array}{lr}\text { Cupón de lunes a viernes } & 49 \% \\ \text { Cuponazo de viernes } & 38 \% \\ \text { Supercupón fin de semana } & 10 \% \\ \text { Extraordinario } & 3 \%\end{array}$

Vide ONCE, «¿A qué les gusta jugar?, Punto de Venta, 40, (2004), p. 14: «El cupón diario tiene una alta tasa de clientes que juegan una o menos veces por semana y cada vez que lo hacen compran un solo cupón. El número de personas que asegura comprar el cupón diario es de aproximadamente nueve millones y medio pero, alrededor de seis millones de jugadores compran con esta frecuencia baja. Los jugadores que compran un día a la semana y cuando lo hacen sólo juegan un cupón diario, es de cinco millones ochocientos mil.

La mitad de los jugadores del cuponazo de viernes, que ascienden a 8.200 .000 personas, compran todos o casi todos los viernes del mes, y algo más de 4.000.000 de jugadores lo hacen con una intensidad alta. Se acercan a los puntos de venta (sea para adquirir la cantidad que sea) todos los sorteos de viernes o aunque no jueguen con tanta frecuencia, cuando lo compran, adquieren más de tres cupones.

El supercupón fin de semana tiene una base de jugadores habituales de un millón y medio, curiosamente cantidad similar que representan el número de jugadores esporádico de este producto.

La base de jugadores del bonocupón es de, aproximadamente, 350.000 personas, lo que representa un $1,2 \%$ en el total de jugadores de algún producto de lotería, y el público habitual y comprador frecuente del Bono viene a ser de 150.000 jugadores».

En la p. 16 precisa: «¿Qué día de la semana es el preferido?. Referente a los días de la semana en los que se suele comprar, el día del sorteo está muy relacionado con el momento de compra. El Cupón Diario en los cuatro días de lunes a jueves concentra su volumen de venta, destacando el miércoles como la jornada en el que más se compra. Los jugadores del Cuponazo adquieren, casi en su totalidad, entre el jueves y el viernes, un $22 \%$ y un $62 \%$ respectivamente, mientras que el Súper Cupón Fin de Semana lo hace un $41 \%$ el viernes y un $32 \%$ entre el sábado y el domingo. En general el jueves es el día en el que más juegos y loterías se consumen, al coincidir varios sorteos y existir la proximidad de otros, como son el Cupón Diario, el Cuponazo de Viernes, la Lotería de Jueves, la Primitiva de Jueves y Sábado y el Euromillones».

35 Vide Resolución de la Secretaría General de Asuntos Sociales, de 30 de enero de 2004 (BOE de 24 de febrero, núm. 47), por el que se da publicidad al reglamento regulador del sorteo del cupón de la ONCE, apéndice 1: Normas del sorteo de lunes a jueves.

Vide ONCE, «¿A qué les gusta jugar?», Punto de Venta, 40, (2004), p. 15: «¿Qué perfil tienen los clientes del cupón diario?. Si se tiene en cuenta el sexo y edad en los jugadores que podríamos denominar ocasionales (aquellos que juegan una vez o menos a la semana), comprobamos que el 53\% son mujeres y aunque los tramos de edad comprendidos entre 25 y 65 años representa un porcentaje de un $15 \%$ en cada uno, el público mayor de 65 años tiene un peso definitorio en este perfil de un $22 \%$. Para sintetizar, el perfil del jugador ocasional del cupón diario es mayoritariamente una mujer y un público mayor de 65 años. En cambio, el perfil del jugador de frecuencia alta y media es casi diez puntos por encima, el número de hombres que de mujeres, y un $60 \%$ son mayores de 45 años. Con todo, hay una base de clientes de unos 3.500.000 que, o bien compran todos los días un cupón, o bien, aunque jueguen menos días a la semana, compran dos o más cupones».

En la p. 17 precisa: «¿Conoce nuestro público los premios del cupón y su precio? El conocimiento que tienen los jugadores del precio y premios del cupón difiere según productos: el precio exacto del $\mathrm{Cu}-$ 
LA COMERCIALIZACIÓN DE LOS JUEGOS DE LA ONCE Y SU INCIDENCIA...

La reforma del producto llevada a cabo, se ha basado fundamentalmente en una subida del premio a las cinco cifras y en la introducción de un gran premio a las cinco cifras más la serie, acompañada de una subida del precio unitario.

\subsubsection{Sorteo del cupón de los viernes, con un premio especial a un sólo cupón de 6 millones de euros ${ }^{36}$}

Otra reforma de gran calado fue la que posibilitó ofrecer un cupón los viernes para reducir la semana laboral de los vendedores a cinco días y que se comunica mediante la Circular $n^{\circ} 45$ de 4 de septiembre de 1985:

«En virtud del Acuerdo del Consejo General de la ONCE, adoptado en las sesiones del 10 de abril y 31 de mayo de 1985, los sorteos ordinarios del cupón pro-ciegos experimentarán diferente configuración todos aquellos cuya celebración coincida en viernes, a partir del 4 de octubre, inclusive, de 1985; razón por la que, a fin de desarrollar convenientemente en el marco de las normas reguladoras de la materia la puesta a la venta de los cupones correspondientes a dichos sorteos, esta Delegación General estima oportuno cursar las instrucciones e informaciones siguientes:

$1^{\circ}$. En base al carácter ordinario que reviste el sorteo del cupón en viernes, los cupones correspondientes se pondrán a la venta a partir de la celebración del sorteo inmediato anterior.

$2^{\circ}$. Las comisiones a obtener por los vendedores lo serán en igual cuantía que las obtenidas en los restantes sorteos ordinarios, teniendo derecho a percibir el 25 por ciento de comisión por la venta de 140 cupones en cada sorteo con valor facial de 100 pesetas unidad y el 15 por ciento por todos aquéllos que expendan sobre los 140 antes citados. [...]».

Por parte del Consejo de Protectorado se determina la cantidad máxima de emisión por sorteo, la cantidad destinada a premios, la distribución de premios por emisión y el precio del cupón.

La introducción de un sorteo de viernes especial el primer viernes de cada mes desde comienzos del año 2003 no obtuvo los resultados esperados, mo-

\footnotetext{
pón Diario lo manifestaron casi un 58\% de los consumidores de este cupón, frente al $41 \%$ que lo acertaron en el caso del Cuponazo, reconociendo no saber el precio del producto del viernes hasta un 39\%. El importe del Supercupón Fin de Semana lo desconoce un 62,6\%. Si hablamos de los premios, tenemos que en el caso del Cupón Diario lo desconocen hasta un 79\%, un 82,8\% en el caso del Cuponazo y hasta un 90,5\% el Supercupón Fin de Semana».

36 Vide Resolución de la Secretaría General de Asuntos Sociales, de 30 de enero de 2004 (BOE de 24 de febrero, núm. 47), por el que se da publicidad al reglamento regulador del sorteo del cupón de la ONCE, apéndice 2: Normas del sorteo de viernes, que ha sido modificado por la Resolución de 15 de abril de 2005, de la Secretaría de Estado de Servicios Sociales, Familias y Discapacidad, que da publicidad a la modificación de determinados aspectos del Reglamento regulador del sorteo del cupón de la ONCE (BOE de 10 de mayo, núm. 111).
} 
tivo por el cual se optó en octubre por realizar una reforma de producto para todos los viernes del mes que si ha alcanzado un resultado más satisfactorio ${ }^{37}$.

El cuponazo del viernes ha obtenido unas ventas que representan el $38,5 \%$ de los ingresos del cupón y el $8,4 \%$ de las ventas del sector de juego público.

\subsubsection{Sorteo del cupón de «Fin de Semana» ${ }^{38}$}

La Comisión Permanente del Consejo General de la Organización Nacional de Ciegos, en el ejercicio de las facultades que le corresponden en virtud del Acuerdo General entre el Gobierno de la Nación y la ONCE en materia de cooperación, solidaridad y competitividad para la estabilidad de futuro de la ONCE, y en virtud de lo establecido en el artículo 7.3 del Real Decreto 358/ 1991, de 15 de marzo, modificado por el Real Decreto 1200/1999, de 9 de julio, tomó el Acuerdo de fecha 25 de septiembre de 2003, que suprimió el sorteo de primer fin de semana inmediato siguiente al primer viernes de cada mes y su sustitución por el producto denominado «Sorteo de Fin de Semana», a partir del 1 de enero de 2004.

Mediante dicho Acuerdo, la Organización simplifica y unifica los sorteos de fin de semana existentes hasta ese momento: «Fin de semana» $\mathrm{y}$ «Fin de semana inmediato siguiente al primer viernes de mes», que pasan a denominarse «Sorteos de Fin de Semana», a partir de la fecha indicada.

De conformidad con los términos del mencionado Acuerdo del Consejo de Ministros de 5 de marzo de 1999, con las facultades del Consejo de Protectorado de la ONCE previstas en el art. 8.3.d) del Real Decreto 358/1991, de 15 de marzo, modificado por el Real Decreto 1200/1999, de 9 de julio, y con el Acuerdo del Consejo de Protectorado de la ONCE de 29 de febrero de 2000 sobre procedimientos y criterios de control de las modalidades de juegos autorizadas a esa Entidad, y previa verificación de la Comisión Permanente del Consejo de Protectorado, realizada en su reunión de 13 de octubre de 2003, se procedió a dar publicidad, como garantía de los derechos de los consumidores, a la nueva estructura de los sorteos de fin de semana del cupón de la ONCE, con efectos de 1 de enero de 2004, mediante la Resolución de la Secretaría General de Asuntos Sociales de 13 de octubre de 2003 (BOE de 18 de noviembre, núm. 276).

\footnotetext{
37 Vide Memoria de la Dirección General de la ONCE, 2003.

38 Vide Resolución de la Secretaría General de Asuntos Sociales, de 30 de enero de 2004 (BOE de 24 de febrero, núm. 47), por el que se da publicidad al reglamento regulador del sorteo del cupón de la ONCE, apéndice 3: Normas del sorteo de fin de semana, que ha sido modificado por la Resolución de 15 de abril de 2005, de la Secretaría de Estado de Servicios Sociales, Familias y Discapacidad, que da publicidad a la modificación de determinados aspectos del Reglamento regulador del sorteo del cupón de la ONCE (BOE de 10 de mayo, núm. 111).
} 
LA COMERCIALIZACIÓN DE LOS JUEGOS DE LA ONCE Y SU INCIDENCIA...

La determinación que efectúa el Consejo de Protectorado es idéntica a la expresada en el apartado anterior.

\subsubsection{Abono semanal: bono-cupón ${ }^{39}$}

La forma de comercialización denominada «Abono Semanal» consiste en un cupón, preimpreso o emitido por terminal de punto de venta, válido para todos los sorteos de carácter periódico que se celebren durante un período de siete días naturales.

El título representativo del abono semanal será un documento que contendrá un único número y su serie, figurando las fechas de los sorteos para los cuales es válido, así como el precio total del cupón.

El «Abono semanal» es un producto que se extiende única y exclusivamente a una semana; por tanto, la ONCE no garantiza, en ningún caso, la continuidad de la numeración destinada a este producto durante períodos superiores a la semana, la disponibilidad continuada de ningún número, así como tampoco su suministro periódico al mismo agente-vendedor. El Abono Semanal adopta como nombre comercial: «Bono-cupón».

\subsubsection{Sorteo de «El Combo» ${ }^{40}$}

La Resolución de la Secretaría de Estado de Servicios Sociales, Familias y Discapacidad de 29 de junio de 2004 (BOE de 11 de agosto, núm. 193) ${ }^{41}$ dispuso la publicación del reglamento regulador del nuevo juego activo de la Organización Nacional de Ciegos Españoles, denominado «El Combo», cuya justificación es la siguiente:

«El actual marco de ordenación de las actuaciones de la ONCE en materia de juego se encuentra regulado [...].

\footnotetext{
${ }^{39}$ Vide Resolución de la Secretaría General de Asuntos Sociales, de 30 de enero de 2004 (BOE de 24 de febrero, núm. 47), por el que se da publicidad al reglamento regulador del sorteo del cupón de la ONCE, apéndice 4: Normas del abono semanal, que ha sido modificado por la Resolución de 15 de abril de 2005, de la Secretaría de Estado de Servicios Sociales, Familias y Discapacidad, que da publicidad a la modificación de determinados aspectos del Reglamento regulador del sorteo del cupón de la ONCE (BOE de 10 de mayo, núm. 111).

${ }^{40}$ Vide diario El País de 16 de octubre de 2004, «La ONCE estrena un juego para los sábados»: «La Organización Nacional de Ciegos Españoles (ONCE) pone a la venta este fin de semana El Combo, un juego activo cuyo primer sorteo se realizará el sábado 23 de octubre, único día de la semana en el que hasta ahora no había un juego de la ONCE. El juego, resultado del acuerdo firmado en febrero entre el Gobierno y la ONCE, está formado por siete bolas: seis agrupadas en forma de triángulo y una adicional, denominada Combola. Hay que seleccionar un número del 0 al 9 para cada una de las seis bolas del triángulo y uno o más números del 1 al 11 para la Combola. Se pueden realizar apuestas múltiples. El juego costará un euro y se destinará a premios el 50\%. La previsión de ingresos es de cuatro millones por sorteo».

${ }^{41}$ Vide Resolución de 15 de julio de 2005, de la Secretaría de Estado de Servicios Sociales, Familias y Discapacidad, que da publicidad a la modificación de determinados aspectos del Reglamento regulador de «El Combo» de la ONCE (BOE de 10 de agosto, núm. 190).
} 
REALA 300-301 (ENERO-AGOSTO, 2006)

Conforme al mismo, el Consejo General de la ONCE está facultado para iniciar el desarrollo de nuevas modalidades de juego, de naturaleza activa o pasiva distinta del cupón, como instrumentos que permitan asegurar la competitividad en el mercado y poder alcanzar el volumen máximo de ventas autorizado a la Organización, con el objetivo de asegurar su estabilidad institucional y el cumplimiento de sus obligaciones sociales y económicas, presentes y futuras.

Asimismo, corresponde al Consejo de Protectorado de la ONCE verificar, con carácter previo a su explotación comercial, que las condiciones de las modalidades de juego concedidas y autorizadas a la ONCE se ajustan a los términos establecidos en el mencionado marco de ordenación de los juegos de azar autorizados a la ONCE, ordenando su publicación como garantía de los consumidores.

En cumplimiento de las anteriores previsiones, el Consejo General de la ONCE ha adoptado acuerdo de fecha 6 de mayo de 2004 sobre: "Aprobación de un nuevo juego activo denominado 'El Combo', y su Reglamento", que ha sido verificado por el Consejo de Protectorado de la ONCE en su reunión ordinaria de 29 de junio de 2004. [...]».

Y en cuyo preámbulo se precisa:

«[...]. La comercialización del juego se realizará mediante boletos preimpresos y boletos emitidos por terminales de punto de venta o mediante la utilización de todos aquellos soportes informáticos, tecnológicos o de comunicación que existan o que puedan existir en el mercado, que presten una garantía plena a los consumidores y a la protección de los menores de edad, de acuerdo con la legislación vigente. Para la introducción de estos nuevos soportes se aprobará, en su momento, una modificación en el presente Reglamento, en el que se contendrá la regulación de los nuevos aspectos necesarios para su implantación plena. [...]».

La venta de los boletos de El Combo sujetos a este nuevo reglamento se inició el 25 de septiembre de 2005, celebrándose el primer sorteo el 1 de octubre. El sorteo tiene carácter periódico y semanal, celebrándose un único sorteo todos los sábados del mes, vendiéndose por todos los agentes vendedores de la ONCE. Se destina a premios el cincuenta por ciento de la recaudación de cada uno de los sorteos. Existen dos tipos de premio: premio de cuantía fija y premios de cuantía variable. Ninguno de los premios, excepto el bote, será acumulativo, debiendo abonar la ONCE al concursante el importe del premio superior que resulte del boleto. El precio de los boletos será de un euro por apuesta en un boleto, en el caso de apuestas múltiples, el precio del boleto será de un euro por cada uno de los números que el concursante haya elegido para la bola adicional.

\subsubsection{Sorteo extraordinario ${ }^{42}$}

Se celebrará uno por trimestre. Podrá ser modificado de forma análoga a la expuesta en el apartado anterior.

42 Vide Memoria de la Dirección General de la ONCE, 2003. 
LA COMERCIALIZACIÓN DE LOS JUEGOS DE LA ONCE Y SU INCIDENCIA...

\subsubsection{Lotería instantánea o presorteada}

En virtud de lo establecido en el Real Decreto 1336/2005, de 11 de noviembre, por el que se autoriza a la ONCE la explotación de una lotería instantánea o presorteada, se adiciona una nueva fórmula cuya autorización tendrá vigencia hasta el 31 de diciembre de 2011, sin perjuicio en su caso, de las ulteriores prórrogas que establezca el Consejo de Ministros.

El Consejo General de la ONCE podrá fijar el precio de cada tarjeta, boleto o soporte unitario, teniendo en cuenta que su precio máximo autorizado de venta será el del límite establecido en cada momento para el cupón que comercializa la ONCE. El programa de cada emisión preverá una cantidad para premios que no podrá ser inferior al 45 por ciento ni superior al 65 por ciento del valor de la emisión. El volumen máximo de ventas y de emisión anual será de 600 y 750 millones de euros, respectivamente para el año 2006. Ambos importes se incrementarán anualmente en función de la variación del índice de precios de consumo real del año anterior, incrementado en tres puntos.

El reglamento regulador del sorteo de lotería instantánea que recoja el diseño o formato de este juego, la emisión del número de series y billetes o ejemplares que la componen, su precio, el programa y forma de pago de los premios y el sistema de revelado, descubierto o apertura de aquéllos, una vez que el Consejo de Protectorado de la ONCE ha verificado que se ajusta a lo dispuesto en este real decreto y a los procedimientos y criterios de control aplicables, se publicará en el BOE como garantía de los consumidores.

\subsubsection{Los que puedan autorizarse en el futuro}

Tal y como dispone el reglamento regulador del sorteo del cupón de la ONCE, Anexo, Preámbulo (Resolución de la Secretaría General de Asuntos Sociales, de 30 de enero de 2004, BOE de 24 de febrero de 2004, núm. 47):

«El cupón puede comercializarse en las modalidades presentes: de lunes a jueves, de viernes, de fin de semana y sorteos extraordinarios, más las que, en el futuro, pudiera autorizar el Consejo General de la $\mathrm{ONCE}^{43}$, conforme a la normativa antes señalada y previos los trámites preceptivos que las indicados normas establecen».

\footnotetext{
43 Vide ONCE, «La ONCE comercializará en exclusiva una lotería instantanea a partir de 2006», Perfiles (Versión electrónica), 211, (2005): «Contamos con los mejores vendedores del mundo que van a explotar, por primera vez en España, un juego instantáneo que ya funciona perfectamente en muchos países de Europa. [...]. La medida desbloquea las negociaciones que los responsables de la organización de ciegos venían manteniendo desde hace meses con representantes del Gobierno que tiene capacidad decisoria en el Protectorado), con vistas a mejorar sus resultados en materia de juego, dado el descenso experimentado por las ventas del cupón y la necesidad de generar nuevos recursos que garanticen el cumplimiento de sus fines sociales.
} 


\section{LA COMERCIALIZACIÓN DE LOS JUEGOS DE LA ONCE EN EL DOMINIO PÚBLICO LOCAL ${ }^{44}$}

\section{El quiosco de la ONCE: hito y rito asentado en el dominio público}

El hecho de ejercer en la calle está configurado por un gran número de connotaciones, en gran medida negativas, que se veían reforzadas en el caso de la ONCE por ser la persona afectada un discapacitado. La calle es un espacio cargado de provisionalidad e incluso de marginalidad, valores que contaminan a las personas que ejercen su labor o desempeñan alguna actividad en dicho espacio. Por todo ello, una iniciativa de gran trascendencia en la dignificación de los vendedores del cupón ha sido el cambio que han experimentado en la escenografía urbana, con la progresiva implantación de quioscos, y que además de ejercer varios papeles funcionales, también representan otros simbólicos.

Sin duda, lo que pretendía la ONCE era proporcionar a sus vendedores un lugar más cómodo en donde desempeñar su labor comercial, al abrigo de las inclemencias del tiempo. También se consigue que desde el punto de vista de la comunicación, los quioscos figuran como espacios físicos de publicidad estática al ubicar el logo de la ONCE en emplazamientos estratégicos ${ }^{45}$.

\footnotetext{
El acuerdo del Consejo de Protectorado regula también el procedimiento de subvención a la ONCE por parte del Ministerio de Hacienda, caso de no cumplirse los objetivos de venta marcados en cada ejercicio. Ambas medidas estaban contempladas en el Acuero General firmado con el Gobierno en febrero de 2004, que tiene vigencia hasta el ejercicio 2011. [...]».

${ }^{44}$ Vide Redacción (Consultas), «Ocupación de la vía pública con quiosco de la ONCE», Actualidad Administrativa, 2, (2005), pp. 230-231.

${ }^{45}$ Vide Antón Álvarez Ruiz, La función social de la publicidad de la ONCE, Escuela Libre Editorial, Madrid, 2003, pp. 163-166: «Pero antes debemos realizar una precisión. Actualmente sólo uno de cada tres vendedores del cupón realiza su trabajo desde un quiosco. No tendría lógica comercial ubicar a todos los vendedores en quioscos, porque hay zonas que se cubren mucho mejor con el sistema de venta ambulante, y prescindir de ésta supondría perder una cuota de mercado realmente importante. Pero aún así, el cambio de imagen, la dignificación laboral y otros aspectos que vamos a comentar, sobrevenidos como consecuencia de la implantación de los quioscos, han afectado positivamente a toda la red de vendedores, incluidos aquellos que siguen realizando su trabajo de forma itinerante».

Además señala los siguientes aspectos positivos: la instalación de quioscos elimina los elementos de provisionalidad; el quiosco invierte los términos en los que se realiza el intercambio comercial del cupón; supone un refuerzo de la percepción de los vendedores como profesionales del sector terciario; facilitan el trato entre personas discapacitadas y no discapacitadas; para el vendedor constituye un símbolo de autoafirmación».
} 


\section{Régimen jurídico de la determinación del precio público por la ocupación de espacio en la vía pública}

\subsection{Consideraciones preliminares}

Resulta frecuente encontrar pleitos que tienen como base la determinación del régimen jurídico-económico del precio por la ocupación del dominio público por los quioscos de la ONCE donde se comercializan todos los juegos que la corporación de derecho público de carácter social explota en nuestro país. Normalmente, lo que se recurre es la liquidación por ocupación de la vía pública. Y normalmente, se suele confundir el «establecimiento o modificación» con la «liquidación», que es cosa distinta ${ }^{46,47}$. La base jurídica sobre

\footnotetext{
${ }^{46}$ Vide Sentencia del TSJM núm. 34/2002 (Sala de lo Contencioso-Administrativo, Sección 4ª), de 18 de enero, Ar. 134077.
}

«FUNDAMENTOS DE DERECHO. [...].

SEGUNDO.- La alegación de inconstitucionalidad de la regulación legal de los precios públicos ha de ser desestimada por la misma razón que en litigios anteriores entre las mismas partes: a) el precio público de que se trata no lo es de una ocupación necesaria sino voluntaria del dominio público local; b) el Tribunal Constitucional ha declarado que la regulación que contiene la Ley de Haciendas Locales es conforme a la Constitución. Para lo primero nos remitimos a las numerosas sentencias dictadas en casos anteriores; para lo segundo, a las sentencias del Tribunal Constitucional 233/99 y 106/2000..

TERCERO.- La alegación de falta de Memoria económico financiera tiene en su contra la existencia de dicho documento incorporado a los autos.

CUARTO.- La alegación esencial de la demanda es la ilegalidad de los criterios de fijación del precio público ya que tratándose de Kioscos del modelo Sevilla cuyas dimensiones son 1'20 x 1'20, es decir, 1'44 $\mathrm{m}^{2}$, el Ayuntamiento considera que la superficie ocupada es de $2 \mathrm{~m}^{2}$ por lo que tal liquidación no se ajusta al dominio público alegado lo que supone un enriquecimiento injusto. Como ha declarado este tribunal en infinidad de ocasiones no puede prosperar el argumento de que el Ayuntamiento obtiene un lucro injusto al establecer sus tarifas en atención al número de metros cuadrados o fracción de éstos ya que este criterio se halla en conformidad no solamente con el sistema seguido normalmente en esta materia, incluso en el ámbito temporal de los tributos propiamente dichos, sino que constituye un criterio válido contra el que no existe ningún motivo para impugnar.

QUINTO.- Por todo ello procede desestimar la demanda originadora del presente procedimiento y ello sin declaración en cuanto a costas al no estimar que consta temeridad o mala fe en el recurrente».

47 Vide Sentencia del Tribunal Superior de Justicia de Madrid, núm. 1019/2000 (Sala de lo Contencioso-Administrativo, Sección $4^{\mathrm{a}}$ ), de 30 de octubre, Ar. 45862.

\section{«FUNDAMENTOS DE DERECHO}

PRIMERO.- En el presente proceso la entidad recurrente impugna las mencionadas liquidaciones de precio público por aprovechamiento de la vía pública con quioscos en ella instalados para la venta de cupones; exponiendo al respecto las alegaciones que se enjuician a continuación. [...].

CUARTO.- Se alega asimismo que los precios públicos, han de fijarse con criterios objetivos y que los seguidos por el Ayuntamiento en el Estudio Económico Financiero carecen de justificación, además de carecer de fecha el aportado. En el enjuiciamiento de esta alegación se advierte que la Memoria o Estudio (el nombre de «estudio» se ha aplicado por el Ayuntamiento a lo que es una verdadera memoria) aportado es el vigente para el ejercicio de 1998, no para el de 1997 a que este pleito se refiere porque esto fue lo que pidió la recurrente en su escrito de proposición de prueba. En cualquier caso, las Memorias o Estudios de aquel y de anteriores ejercicios son conocidas tanto por el Tribunal como por la recurrente en los numerosos pleitos referidos a la misma exacción que el presente, lo que permite en- 
la que se sustentan las alegaciones versa normalmente sobre la falta de memoria económico financiera, o el cuestionamiento de la objetividad de los criterios seguidos por las Corporaciones Locales, lo que sin duda ha obligado a los tribunales a pronunciarse en reiteradas ocasiones sobre el particular, llegando a precisar que la ley permite que se fijen los precios públicos atendiendo al valor de mercado o de la utilidad derivada de la utilización privativa o aprovechamiento especial del dominio público. Eso sí, al tratarse del ejercicio de una potestad administrativa, debe hacerlo no sólo sometido al derecho, sino de forma razonablemente ponderada y siempre bajo el control del poder judicial.

\subsection{La jurisprudencia del Tribunal Constitucional}

Particular importancia tiene la STC 106/2000 (Pleno), de 4 de mayo, que ha establecido la interrelación entra la legislación estatal y las atribuciones que corresponden a los Ayuntamientos:

«[...] nuestro pronunciamiento debe contraerse al apartado A) del art. 41 LHL, dado que en todos los procesos se han impugnado exclusivamente precios públicos por la utilización privativa o aprovechamiento especial del dominio público, en particular, por la instalación en la vía pública local de quioscos autorizados para la venta del cupón de la ONCE [...] (F.J. $1^{\circ}$ ).

[...]. Así es, por lo que se refiere al art. 48.1 LHL -que, a juicio de los Tribunales Superiores de Justicia de Canarias, Castilla y León y Galicia, vulneraría la reserva de ley, por lo que atañe al presente proceso, al admitir que el Pleno de la Cor-

\footnotetext{
juiciar las alegaciones relativas a los criterios que sigue el Estudio; y al respecto se estima que tener en cuenta los precios de los arrendamientos es un modo correcto de llegar al valor económico de la utilización de un bien tan singular como la vía pública. Tampoco un coeficiente del $11 \%$ puede considerarse arbitrario aunque también pueda valer como tipo para intereses de demora, como tampoco carece de toda justificación el incremento del $40 \%$ para los puestos permanentes no desmontables.
}

QUINTO.- Con base en el informe pericial emitido en otro recurso ( $\left.{ }^{\circ} 1191 / 96\right)$ la recurrente llega a la conclusión de que los precios fijados son superiores a los de mercado.

El Tribunal, tomando dicho informe, aportado como prueba documental, como dictamen pericial en los razonamientos que en él se exponen y por su referencia a vías públicas del mismo Distrito municipal que las de ese pleito, aprecia dicha prueba como dispone el artículo 632 de la Ley de Enjuiciamiento Civil, según las reglas de la sana crítica y sin estar obligado a sujetarse a lo dictaminado; y en esa apreciación advertimos, una vez más, la ausencia del valor económico que significa la vía pública. Dentro de las grandes dificultades que se ofrecen a la hora de fijar un valor económico cualquiera, esas dificultades disminuyen cuando se trata del valor de mercado, en que su fijación coincide con la simple observación o información de lo que en el mercado ocurre, sin más complicaciones. En el caso de la vía pública, sin embargo, el verdadero valor de mercado vendría dado por la concurrencia de distintas personas que pretendieran ocupar el mismo lugar, adjudicándose a la mejor oferta; o también fijando previamente el precio y esperando a que interese a algún comerciante en libre decisión. En todo caso la vía pública añade el efecto económico inherente al hecho de que el oferente de un producto sale al paso del viandante desde su instalación. Estas particularidades completan la consideración normativa de que «el valor de mercado» que menciona el artículo 45.2 de la Ley de Haciendas Locales es una «referencia», según la propia dicción legal». 


\section{LA COMERCIALIZACIÓN DE LOS JUEGOS DE LA ONCE Y SU INCIDENCIA...}

poración establezca los precios públicos por la ocupación del dominio público al margen de cualquier determinación legal-, comenzábamos en el F. 18 de la STC 233/1999 destacando, en la línea de pronunciamientos anteriores, que la reserva de ley de los arts. 31.3 y 133 CE no es absoluta, sino que permite la colaboración del reglamento, especialmente en las prestaciones como los precios públicos que, sin dejar de ser impuestas, responden a un esquema sinalagmático. Y aunque el art. 41 A) LHL, del mismo modo que hacía el art. 6 LTPP, se limita a hacer una definición abstracta de los precios públicos, de manera que el art. 48.1 LHL remite al Pleno de la Corporación el establecimiento concreto de las utilizaciones privativas o aprovechamientos del dominio público que darán lugar a la exacción de la prestación de carácter público, también dijimos que, cuando estamos ante un recurso propio de las Haciendas locales (concretamente, en este caso, ante prestaciones de naturaleza materialmente tributaria), la ley debe reconocerles una intervención en su establecimiento o en su exigencia, sin que «el legislador pueda limitarse a una mera mediación formal apoderando a los Ayuntamientos para conformar el tributo, sin predeterminación alguna». Es evidente, sin embargo, concluíamos en el mismo fundamento, «que una abdicación tal de lo que, por mandato constitucional (arts. 31.3, 133.1 y 133.2 CE), corresponde al legislador, no se ha producido en este caso, dado que la LHL delimita el presupuesto de hecho de los precios públicos en términos lo suficientemente precisos como para circunscribir adecuadamente la decisión de los Municipios». En concreto, por lo que al apartado A) del art. 41 LHL respecta, éste especifica que tendrán la consideración de precios públicos las contraprestaciones pecuniarias que se satisfagan por la utilización privativa o aprovechamiento especial del dominio público local; y, «además de que la utilización privativa y el aprovechamiento especial constituyen rancias y consolidadas expresiones técnico-jurídicas cuya definición se encuentra en la normativa vigente [...]». «No es posible, pues, entender que la intervención que la LHL otorga a los Municipios en un ingreso propio de carácter materialmente tributario como son los precios públicos constitutivos de prestaciones de carácter público excede de los límites derivados de la reserva de ley de los arts. 31.3 y 133 CE», por lo que «debe concluirse que la atribución que el primer inciso del art. 48.1 LHL hace al Pleno de la Corporación para que establezca o modifique los precios públicos respeta la reserva de ley tributaria» (F.J. $2^{\circ}$ ).

[...]. Esto sentado, llegábamos a la conclusión de que el art. 45.2 LHL respeta el principio de legalidad tributaria en relación con los precios públicos por la utilización privativa o aprovechamiento especial del dominio público, al imponer «a la Administración a la hora de fijar la cuantía de la prestación de carácter público la obligación de circunscribirse, dentro de una razonable esfera de apreciación, a unos criterios de naturaleza técnica que no puede obviar, discrecionalidad técnica que debe estimarse respetuosa con las exigencias de la reserva de ley siempre que, como aquí acontece, tal discrecionalidad pueda considerarse circunscrita de modo que asegure una continua garantía a los interesados frente a posibles arbitrios de la Administración». Basta la mera lectura del precepto — decíamos- para constatar que «éste no establece un mínimo por encima del cual los Entes locales pueden decidir sin ataduras la cuantía de la prestación patrimonial, sino que recoge presu- 

de decisión de los poderes públicos» (F.J. $\left.3^{\circ}\right)^{48}$.

Las conclusiones que podemos extraer son las siguientes: primera, la intervención que la LHL otorga a los Municipios, atribuye al pleno de la corporación la posibilidad de establecer o modificar los precios públicos, y este pronunciamiento implica el respeto escrupuloso a la reserva de ley tributaria. Segunda, se debe respetar el principio de legalidad en relación con la

\footnotetext{
48 Vide Emilio Rouanet Mota, «Ocupación del dominio público local por quioscos de la ONCE», Actualidad Administrativa, referencia LV, (2002): «Debe hacerse antes de entrar en el análisis del fondo del debate planteado, una precisión, y es la de que, en el presente caso de autos, en el que las liquidaciones corresponden a unos meses de 1993, resultan intrascendentes el tenor y los efectos de las sentencias del Tribunal Constitucional 233/1999, de 16 de diciembre, y 106/2000, de 4 de mayo, [...].
}

Es opinión de quien suscribe que lo procedente es considerar que tanto la solución arbitrada por la sentencia recurrida como las liquidaciones que son objeto de controversia están atemperadas al ordenamiento jurídico, en tanto en cuanto:

1. Como ya ha dejado sentado el Tribunal Constitucional, el art. 45.2 de la Ley 39/1988 respeta el principio de legalidad tributaria en relación con los precios públicos por la utilización privativa o aprovechamiento especial del dominio público local, al imponer a la Administración, a la hora de fijar la cuantía de la prestación de carácter público, la obligación de circunscribirse, dentro de una razonable esfera de apreciación, a unos criterios de naturaleza técnica que no puede obviar, discrecionalidad técnica que debe estimarse respetuosa con las exigencias de la reserva de ley siempre que, como aquí acontece, tal discrecionalidad pueda considerarse circunscrita de modo que asegure una continua garantía a los interesados frente a posibles arbitrariedades de la Administración. [...].

En efecto, tanto el valor de mercado como la utilidad derivada del aprovechamiento especial -que en la sentencia del Tribunal Constitucional 185/1995 se calificaba, desde la perspectiva del principio de seguridad jurídica, como una fórmula de cuantificación de los precios públicos suficientemente claraconstituyen criterios de indudable naturaleza técnica a los que la Administración Local tiene necesariamente que acudir a la hora de determinar el importe de los precios públicos por la ocupación del dominio público.

Ciertamente, el contenido exacto de tales magnitudes depende de variables a menudo inciertas; pero no es dudoso que tales variables y, por tanto, tales magnitudes no son el resultado de una decisión antojadiza, caprichosa y, en definitiva, arbitraria del ente público, cuando, a mayor abundamiento, constituye una garantía de la imparcialidad de la Administración el control que, al efecto, establece el art. 26.2 de la Ley 8/1989 — de aplicación supletoria al ámbito local en virtud de la Disposición Adicional Séptima de la citada Ley_, al señalar que «toda propuesta de fijación o modificación de precios públicos deberá ir acompañada de una «Memoria Económico-financiera» que justificará ..., en su caso, las utilidades derivadas de la realización de actividades y la prestación de los servicios o los valores de mercado —o de utilidad — que se hayan tomado como referencia.

Doctrina recogida, asimismo, en las sentencias antes reseñadas, en el sentido de que «el establecimiento de una carga patrimonial de carácter público exige la observancia rigurosa de las normas que la permiten y regulan, especialmente en sus elementos cuantitativos, sin que sean posibles interpretaciones extensivas o analógicas y, menos, la actuación sin limitación alguna, peor aún que si se tratara de una actividad negocial privada, sometida sólo a las leyes de mercado, pues en los precios públicos no existen ni siquiera las limitaciones que impone el juego de la oferta y de la demanda». [...].

En efecto, el Ayuntamiento, atendiendo sólo a razones de gestión tributaria, liquida, junto al precio público por ocupación de la vía pública con los quioscos, la tasa por prestación del servicio de recogida de basuras, [...].

No hay, tampoco, base para aceptar la argumentación de que «las tarifas se están aplicando de forma lineal, sin hacer distinción de la categoría de las vías públicas en donde se encuentran instalados los quioscos», pues la Ordenanza Fiscal establece una diferente cuantía del precio público según el quiosco esté ubicado en calle de primera categoría, de segunda, $[\ldots] »$ 
LA COMERCIALIZACIÓN DE LOS JUEGOS DE LA ONCE Y SU INCIDENCIA...

utilización privativa o aprovechamiento especial del dominio público. La Administración tiene la obligación de circunscribirse, dentro de una razonable esfera de apreciación, a unos criterios de naturaleza técnica que no puede obviar, discrecionalidad técnica que debe ser respetuosa con las exigencias de la reserva de ley. De este modo, se garantiza un trato justo al administrado, frente a una posible arbitrariedad de la Administración.

\subsection{La jurisprudencia del Tribunal Supremo}

La STS (Sala de lo Contencioso-Administrativo, Sección $2^{\mathrm{a}}$ ), de 15 de abril de 2000, Ar. 3023, F.D. Cuarto, ha determinado: «[...]. La Ley permite que se fijen los precios públicos atendiendo al valor de mercado o de la utilidad derivada de la utilización privativa o aprovechamiento especial del dominio público, ya se elija uno u otro módulo o se ponderen ambos, como reconoció posible la Sentencia de 15 de enero de 1998, pero sin que sea admisible aplicar otros criterios más que los previstos en la Ley, ni olvidar que el precio, aunque se adjetiva de «público», es siempre la contraprestación pecuniaria de la adquisición de un bien o del arrendamiento de un bien o de un servicio y por lo tanto, aunque - como ya hemos dicho- a diferencia de las tasas, que no pueden rebasar el coste estimado, sea posible la obtención de un beneficio, éste no puede concebirse limitado y sujeto sólo a la voluntad del vendedor o arrendador que, precisamente por que actúa en el ejercicio de la potestad administrativa, ha de hacerlo no sólo sometido al derecho, sino de forma razonablemente ponderada y siempre bajo el control de los Tribunales».

Y respecto a la memoria económico-financiera, la STS (Sala de lo Contencioso-Administrativo, Sección $2^{\mathrm{a}}$ ), de 19 de mayo de 2000, Ar. 4230, F.D. $3^{\circ}$, precisa: «[...]. Por otra parte no es indiferente la existencia o no, con las debidas formalidades y contenido, de una verdadera Memoria Económica Financiera como estudio antecedente de la decisión normativa del establecimiento del precio público, que no puede soslayarse o cumplirse formulariamente.

En este sentido la redacción por el arquitecto municipal de una valoración de suelo no puede considerarse suficiente a los efectos de integrar en la referida Memoria, cuestión que, por otra parte, corresponde, en gran medida, a la valoración probatoria del contenido del expediente sobre lo que no cabe discutir en casación».

\section{Responsabilidad patrimonial: la competencia sobre la conservación y policía del dominio público municipal}

La responsabilidad en estos supuestos corresponderá a las corporaciones locales ${ }^{49}$. En términos generales, se alega por la Administración que el man-

\footnotetext{
${ }^{4}$ Vide Sentencia del Tribunal Superior de Justicia de Murcia, núm. 892/1999 (Sala de lo Contencioso-Administrativo, Sección $2^{\mathrm{a}}$ ), de 2 de noviembre, Ar. 21123:
} 


\section{tenimiento y conservación de la zona próxima al quiosco de la ONCE le in- cumbe a la corporación de derecho público de carácter social. Aunque eso}

\section{«FUNDAMENTOS JURÍDICOS}

PRIMERO.- Son hechos probados que se desprenden del contenido del expediente administrativo y de la prueba practicada los siguientes:

Sobre las 18:20 horas del día 2 de noviembre de 1.995, Dña. Carmen G. R. sufrió una caída en la Calle Gloria de Santomera, debido a que la tapa de la arqueta en que se encuentra la conducción de suministro eléctrico de un cercano kiosco de la O.N.C.E., cedió al ser pisada. Como consecuencia de la caída la Sra. G. R. sufrió lesiones de las que tardó en curar 190 días, quedándole como secuela una ligera gonalgia postoperatoria (después de la Meniceptomía), que se encuentra sin baremar ni evaluar. La lesionada tuvo que afrontar gastos de farmacia, ortopedia y consulta de podología por un total de 23.072 pesetas.

SEGUNDO.- Por la fecha de los hechos, 2 de noviembre de 1.995, el régimen jurídico de la reclamación está contenido en el art. 54 de la Ley 7/85 de 2 de abril, Reguladora de las Bases del Régimen Local, que establece la responsabilidad directa de las Entidades Locales por los daños y perjuicios causados a los particulares en sus bienes y derechos como consecuencia del funcionamiento de los servicios públicos, remitiéndose a lo dispuesto en la legislación general sobre responsabilidad administrativa, que viene constituida por los artículos 139 y siguientes de la Ley 30/92.

Los hechos que se declaran probados derivan de los elementos probatorios contenidos en el propio expediente administrativo; así como de la prueba practicada en este procedimiento.

Señala el T.S. en sentencia de 11 de febrero de 1.991 que para el éxito de la acción de responsabilidad, reconocida al más alto nivel normativo en el art. 106-2 C.E., se precisa, según constante jurisprudencia: a) la efectiva realidad de un daño evaluable económicamente e individualizado en relación con una persona o grupo de personas; b) que el daño o lesión patrimonial sufrido por el reclamante sea consecuencia del funcionamiento normal o anormal de los servicios públicos en una relación directa, inmediata y exclusiva de causa efecto, sin intervenciones extrañas que alteren el nexo causal; y c) que no se haya producido fuerza mayor.

Según reiterada jurisprudencia la responsabilidad patrimonial de la Administración es objetiva. «Esta fundamental característica impone que no sólo no es menester demostrar para exigir aquella responsabilidad que los titulares o gestores de la actividad administrativa que ha generado un daño han actuado con dolo o culpa, sino que ni siquiera es necesario probar que el servicio público se ha desenvuelto de manera anómala, pues los preceptos constitucionales y legales que componen el régimen jurídico aplicable extienden la obligación de indemnizar a los casos de funcionamiento normal de los servicios públicos.

Debe, pues, concluirse que para que el daño concreto producido por el funcionamiento del servicio a uno o varios particulares sea antijurídico basta con que el riesgo inherente a su utilización haya rebasado los límites impuestos por los estándares de seguridad exigibles conforme a la conciencia social. No existirá entonces deber alguno del perjudicado de soportar el menoscabo y, consiguientemente, la obligación de resarcir el daño o perjuicio causado por la actividad administrativa será a ella imputable» (S.T.S. de 5 de junio de 1997, Pte. Sr. Xiol).

No hay duda de que la reclamante ha sufrido una lesión evaluable económicamente. Consecuentemente, la atención debe centrarse en el estudio de la concurrencia de los otros elementos que dan lugar al nacimiento de responsabilidad de la Administración, así como, en caso de que concurran, proceder a la evaluación del daño.

TERCERO.- Cuestión de examen preferente es la relativa a si nos encontramos ante un servicio publico.

Con carácter general, los servicios públicos no deben ser entendidos en sentido estricto como una concreta modalidad de la acción administrativa, sino en un sentido amplio y predominantemente subjetivo, que incluya a toda la actividad e incluso inactividad por omisión de obligaciones de actuar de cualquier Administración Pública.

De conformidad con el art.25-2 d) L.R.B.R.L. es de competencia municipal la materia propia de «pavimentación de vías públicas», siendo un servicio que el Ayuntamiento de Santomera está obligado a pres- 
sea así, de acuerdo con el artículo $80.8^{\circ}$ del Reglamento de Bienes de las Corporaciones Locales, lo que también es cierto es que al Ayuntamiento le corresponde controlar la utilización que del espacio demanial se haga por el concesionario de forma que la concesión no exime al Ayuntamiento de ejercer su competencia sobre la conservación y policía del dominio público municipal.

tar de acuerdo con el art.26-1 a) de la misma Ley, sin que conste que exista la dispensa autonómica prevista en el apartado $2^{\circ}$ del art. 26. Además, esta obligación se correlaciona con el derecho de los vecinos al establecimiento y prestación del servicio, consagrado en el art.18-1-g) del mismo Texto Legal.

Se alega por la Administración que el mantenimiento y conservación de la arqueta y de su tapa incumbían a la O.N.C.E. Aunque eso así sea de acuerdo con el artículo $80.8^{\circ}$ del Reglamento de Bienes de las Corporaciones Locales, lo que también es cierto es que al Ayuntamiento corresponde controlar la utilización que del espacio demanial se haga por el concesionario de forma que la concesión no exime al Ayuntamiento de ejercer su competencia sobre la conservación y policía del dominio público municipal.

Lo anterior lleva a la conclusión de que nos encontramos indudablemente ante un supuesto característico de prestación de servicio público en sentido estricto.

CUARTO.- La siguiente cuestión a determinar es la de si la lesión es consecuencia del funcionamiento del servicio público y que se encuentren éste y aquélla en relación de causa a efecto, lo que nos introduce en el estudio del título de imputación a la Administración titular del servicio y del nexo causal..

Para determinar si las circunstancias de la vía eran o no las exigibles hay que conectar las circunstancias concretas del caso con el rendimiento medio o estándar exigible al servicio, con las dificultades que entraña la definición del contenido del concepto jurídico «rendimiento medio» dado su carácter indeterminado.

La prueba practicada demuestra que las lesiones fueron consecuencia de que cediera la tapa del registro que se encontraba situado en la acera, sin que se haya probado, ni siquiera alegado, que haya concurrido fuerza mayor determinante de la ruptura del nexo causal, o que las circunstancias de la acera se encuadrasen dentro del estándar exigible al funcionamiento del servicio. Esto último es, además, obvio que no ocurre, puesto que es inadmisible que un servicio elemental, como el de la pavimentación de las vías públicas, ofrezca riesgos capaces de causar lesión a los propios beneficiarios del servicio.

QUINTO.- Para la determinación de la cuantía indemnizatoria, existiendo secuelas a valorar, debe distinguirse entre éstas y los días de baja.

En relación con los últimos, la cuestión se reduce a fijar una suma por cada uno de los 190 días que tardó la recurrente en alcanzar la curación, tal como consta en informe pericial practicado en periodo probatorio, que, según criterio de esta Sala, se valora a razón de 8.000 pesetas por día.

En lo relativo a la secuela concretada en dicho informe, su valoración debe diferirse al periodo de ejecución de sentencia, en el que, a petición de la actora, se deberá fijar, huyendo de criterios subjetivos y siguiendo el criterio de esta Sala, de acuerdo con el baremo aprobado por la Ley de Uso y Circulación de Vehículos de Motor, en la redacción dada por la Ley de Ordenación de Seguros Privados de 8 de noviembre de 1.995 .

Por último, también son indemnizables los gastos acreditados de 23.072 pesetas, lo que arroja un total, sin contar secuelas, de 1.543 .072 pesetas». 